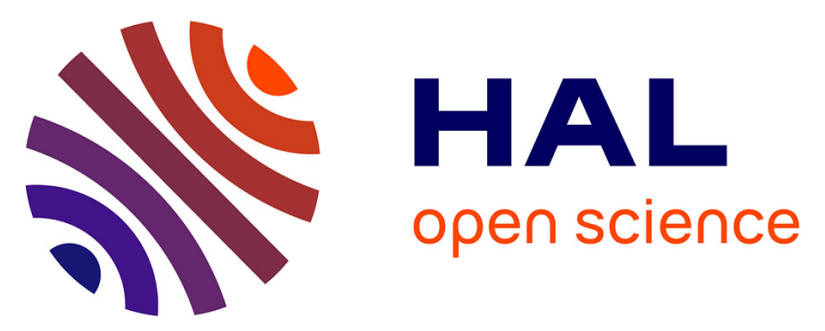

\title{
Synthesis, Spectroelectrochemical Behavior, and Chiroptical Switching of Tris $(\beta$-diketonato) Complexes of Ruthenium(III), Chromium(III), and Cobalt(III)
}

Miguel Cortijo, Christine Viala, Thibault Reynaldo, Ludovic Favereau, Isabelle Fabing, Monika Srebro-Hooper, Jochen Autschbach, Nicolas Ratel-Ramond, Jeanne Crassous, Jacques Bonvoisin

\section{To cite this version:}

Miguel Cortijo, Christine Viala, Thibault Reynaldo, Ludovic Favereau, Isabelle Fabing, et al.. Synthesis, Spectroelectrochemical Behavior, and Chiroptical Switching of Tris( $\beta$-diketonato) Complexes of Ruthenium(III), Chromium(III), and Cobalt(III). Inorganic Chemistry, 2017, 56 (8), pp.4555-4567. 10.1021/acs.inorgchem.6b03094 . hal-01505462

\section{HAL Id: hal-01505462}

\section{https://hal-univ-rennes1.archives-ouvertes.fr/hal-01505462}

Submitted on 6 Sep 2017

HAL is a multi-disciplinary open access archive for the deposit and dissemination of scientific research documents, whether they are published or not. The documents may come from teaching and research institutions in France or abroad, or from public or private research centers.
L'archive ouverte pluridisciplinaire HAL, est destinée au dépôt et à la diffusion de documents scientifiques de niveau recherche, publiés ou non, émanant des établissements d'enseignement et de recherche français ou étrangers, des laboratoires publics ou privés. 


\section{Synthesis, spectroelectrochemical behavior and}

\section{chiroptical switching of tris( $\beta$-diketonato)}

\section{complexes of $\mathrm{Ru}(\mathrm{III}), \mathrm{Cr}(\mathrm{III})$, and $\mathrm{Co}(\mathrm{III})$}

Miguel Cortijo, ${ }^{a}$ Christine Viala, ${ }^{a}$ Thibault Reynaldo, ${ }^{b}$ Ludovic Favereau, ${ }^{b}$ Isabelle Fabing, ${ }^{c}$ Monika Srebro-Hooper, ${ }^{d,}{ }^{*}$ Jochen Autschbach,,${ }^{e, *}$ Nicolas Ratel-Ramond, ${ }^{a}$ Jeanne Crassous, ${ }^{b, *}$ and Jacques Bonvoisin ${ }^{a *}$

${ }^{a}$ CEMES, CNRS UPR 8011, Université de Toulouse, 29 Rue Jeanne Marvig, BP 94347, 31055 Toulouse Cedex 4, France. E- mail: jbonvoisin@cemes.fr

${ }^{b}$ Sciences Chimiques de Rennes UMR 6226, CNRS-Université de Rennes 1, Campus de Beaulieu, 35042 Rennes Cedex, France. E-mail: jeanne.crassous@univ-rennes1.fr

${ }^{c}$ UMR CNRS 5068, LSPCMIB, Université Paul Sabatier, 118 route de Narbonne, 31062 Toulouse Cedex 9, France.

${ }^{d}$ Faculty of Chemistry, Jagiellonian University, R. Ingardena 3, 30-060 Krakow, Poland. Email: srebro@chemia.uj.edu.pl

${ }^{e}$ Department of Chemistry, University at Buffalo, State University of New York, Buffalo, NY 14260, USA. Email: jochena@buffalo.edu

KEYWORDS. tris( $\beta$-diketonato) complexes, spectroelectrochemistry, electronic circular dichroism, chiroptical switching, quantum-chemical calculations. 
ABSTRACT. Five tris( $\beta$-diketonato) complexes of ruthenium(III), chromium(III), and

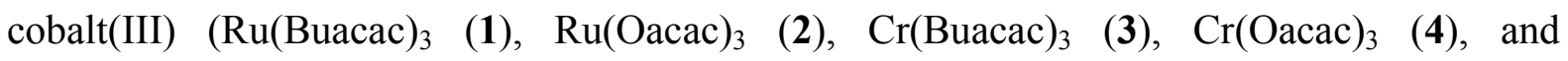
$\mathrm{Co}(\text { Buacac })_{3}(5)$, Buacac $=3$-butylpentane-2,4-dionato, Oacac $=3$-octylpentane-2,4-dionato $)$ with a chiral propeller-like structure have been prepared. Ligands and complexes syntheses are presented together with the characterization of the compounds by ${ }^{1} \mathrm{H}$ - and ${ }^{13} \mathrm{C}-\mathrm{NMR}$, mass spectrometry, IR, UV-vis, electronic circular dichroism (ECD) spectroscopy, electrochemistry studies, and first-principles calculations. The crystal structures of $\mathbf{1}$ and $\mathbf{5}$ have also been obtained and analyzed. A comparison of the ${ }^{1} \mathrm{H}-\mathrm{NMR}$ spectra of diamagnetic (ligands and 5) and paramagnetic species (1 and 2) is presented. The optical resolution of the five complexes has been achieved for the first time by supercritical fluid chromatography using a chiral column, giving rise to very high purity grades in all cases. ECD measurements and calculations for 1-5 have led to the assignment of the absolute configuration, $\Delta$ or $\Lambda$, of each enantiomer. Spectroelectrochemical UV-vis and ECD studies have been performed on $\mathrm{Ru}$ A-2 and $\mathrm{Cr}$ A-4 complexes revealing their redox-triggered chiroptical switching activity and the non-innocence character of the $\beta$-diketonate ligands.

\section{Introduction}

Tris( $\beta$-diketonato) such as tris(pentane-2,4-dionato) complexes are intrinsically chiral because of their propeller-like structure that displays an idealized $D_{3}$ symmetry. They present two possible configurations, $\Delta$ or $\Lambda$, that can be determined by the principle of the skew-line convention (Figure 1). ${ }^{1-2}$ This type of compounds has been attracting a great deal of attention as dopants in (achiral) nematic liquid crystals (NLCs) to form chiral LCs, also known as cholesteric LCs (CLCs), ${ }^{3-11}$ which exhibit a twisted molecular arrangement. The first example of such strategy was reported by Spada and coworkers, ${ }^{3}$ who proved the high ability of 
enantiomerically pure $\mathrm{M}(\mathrm{acac})_{3}$ complexes with $\mathrm{M}=\mathrm{Co}, \mathrm{Cr}, \mathrm{Ir}, \mathrm{Rh}, \mathrm{Ru}$, and acac = acetylacetonate (pentane-2,4-dionate) ion to induce chirality in liquid crystals. The $\mathrm{M}(\mathrm{acac})_{3}$ display however a limited solubility in NLC at room temperature and therefore the use of acac ligands with elongated substituents has been shown more convenient. ${ }^{3-11}$ LCs may also undergo macroscopic structural transformations due to photo-induced conformational changes of a dopant. ${ }^{6-11}$ For example, Horie and coworkers studied the photoracemization of chromium(III) complexes $\mathrm{Cr}($ Buacac $){ }_{3}{ }^{7-8}$ or $\mathrm{Cr}(\mathrm{Oacac}){ }_{3}{ }^{6}$ dissolved in a NLC, demonstrating the chiroptical induction of a periodic stripe texture known as cholesteric fingerprint texture of LC under the irradiation of visible circularly polarized light. This may allow the control of the helical twist sense in a CLC and, consequently, the control of the handedness of circularly polarized reflected light, i.e. chirality of a CLC. ${ }^{12}$

$\beta$-Diketonato ruthenium complexes bearing $\pi$-conjugated ligands are also known to display electroactive properties. In this domain, many carbon-rich, polyimine, quinonoid, diketonato, cyclometalated, and carbenic $\mathrm{Ru}(\mathrm{II})$ or $\mathrm{Ru}(\mathrm{III})$ complexes have been quite recently reported. ${ }^{13-23}$ All these compounds possess at least one organic extended $\pi$-conjugated ligand with non-innocent behavior, which means that induced upon redox process charge density is localized not only on the metal ion, but also supported by the ligand itself. Surprisingly, to the best of our knowledge, ${ }^{24-29}$ the spectroelectrochemical properties and redox chiroptical switching of the parent tris( $\beta$-diketonato) transition metal complexes $M(\text { acac })_{3}$ have never been studied, although the acac ligands are $\pi$-conjugated and their $\pi$-electron system can readily interact with the metal center. 


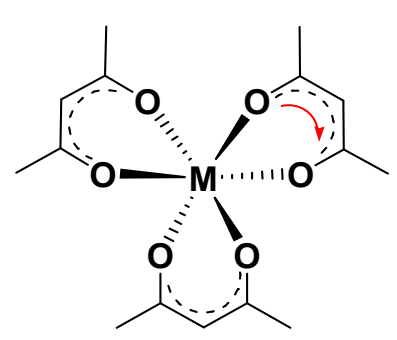

$\Delta$

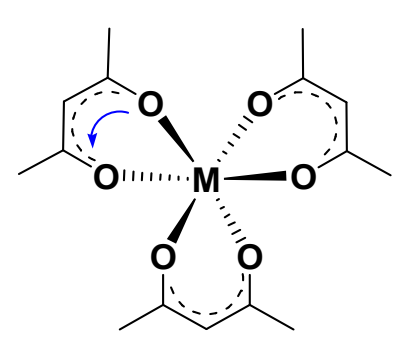

$\Lambda$

Figure 1. Representation of $\Delta$ and $\Lambda$ enantiomers of a tris( $\beta$-diketonato) $\mathrm{M}(\mathrm{III})$ complex.

Taking all this into account, we have prepared five chiral tris( $\beta$-diketonato) complexes based on $\mathrm{Ru}(\mathrm{III}), \mathrm{Cr}(\mathrm{III})$, and $\mathrm{Co}(\mathrm{III})$ transition-metal centers with ligands containing elongated alkyl substituent in the 3-position of the pentane-2,4-dionate (acac) ion, $\operatorname{Ru}(\text { Buacac })_{3}(\mathbf{1}), \operatorname{Ru}(\text { Oacac })_{3}(2), \operatorname{Cr}(\text { Buacac })_{3}(3), \operatorname{Cr}(\text { Oacac })_{3}$ (4), and $\mathrm{Co}(\text { Buacac })_{3}(5)$ (see Figure 2), that thanks to increased solubility in liquid crystals may be promising candidates for future applications in, for example, doping liquid crystals. The systems have been fully characterized by NMR spectroscopy, mass spectrometry, cyclic voltammetry, single-crystal X-ray diffraction studies, IR, UV-vis, and electronic circular dichroism (ECD) spectroscopies. The optical resolution of several examples of similar compounds has been achieved using either a conventional chromatographic column packed with a $\Delta$ $\left[\mathrm{Ru}(\text { phenanthroline })_{3}\right]^{2+}$ system $^{24-25}$ or HPLC with different chiral columns. ${ }^{5-6,26,30-32}$ However, to the best of our knowledge, this is the first time that supercritical fluid chromatography (SFC) has been employed to optically resolve this type of complexes. Absolute configuration (AC) of all the enantiomers was assigned by comparison of the measured ECD spectra with those of similar compounds in the literature ${ }^{33}$ and the simulated ones based on first-principles calculations. Finally, the electroactive properties of these complexes enabled to evaluate their ability to act as chiroptical switches and the effect of redox activity on their electronic and optical properties has been rationalized with a help of quantum-chemical calculations. 

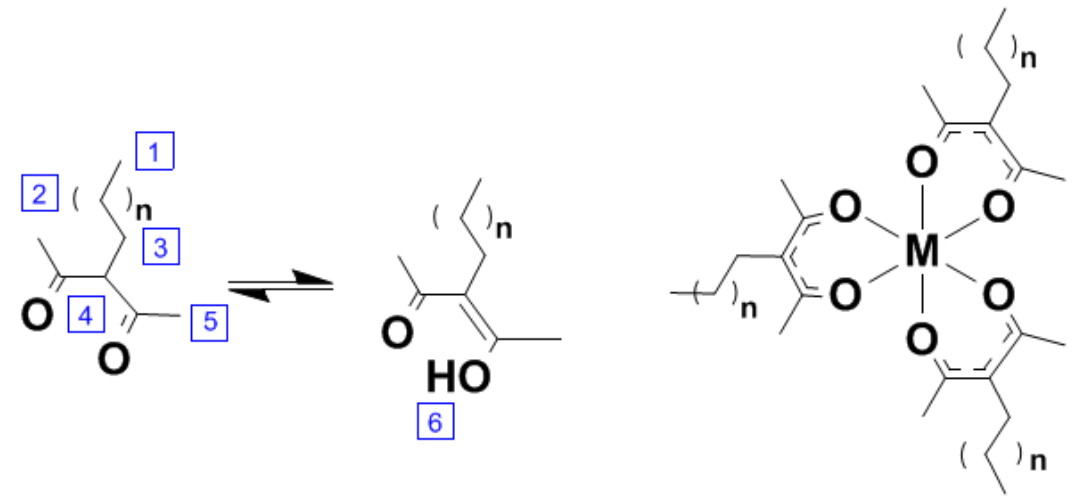

$$
\begin{array}{ll}
\mathrm{n}=2 & \text { (Buacac) } \\
\mathrm{n}=6 & \text { (Oacac) }
\end{array}
$$$$
\begin{aligned}
& M=R u ; n=2(1) \\
& M=R u ; n=6(2) \\
& M=C r ; n=2(3) \\
& M=C r ; n=6(4) \\
& M=C o ; n=2(5)
\end{aligned}
$$

Figure 2. (Left): Acetylacetonate-based ligands presented in this work. The numbering employed to assign the ${ }^{1} \mathrm{H}-\mathrm{NMR}$ data is depicted in blue. (Right): The corresponding metal complexes studied.

\section{Experimental section}

\section{Materials}

All chemicals and solvents were of reagent grade or better. Sodium pentane-2,4-dionate was prepared according to a published procedure. ${ }^{34}$ The ligands and complexes were purified prior to the supercritical fluid chromatography (SFC) by column chromatography using silica gel of high-purity grade for flash chromatography (Fluka). Analytical thin layer chromatography (TLC) was carried out using silica gel on TLC Al foils with fluorescence indicator at $254 \mathrm{~nm}$ (Fluka). 


\section{Physical measurements}

IR spectra were measured on a Perkin Elmer Spectrum 100 FT-IR spectrometer with samples as $\mathrm{KBr}$ pellets. UV-visible spectra were recorded on a Varian Cary 5000 spectrophotometer. Cyclic voltammograms were obtained with an Autolab system (PGSTAT100) in $\mathrm{CH}_{2} \mathrm{Cl}_{2}\left(0.1 \mathrm{M}\right.$ tetrabutylammonium hexafluorophosphate, $n-\mathrm{Bu}_{4} \mathrm{NPF}_{6}=$ $\mathrm{TBAPF}_{6}$, as supporting electrolyte) at $25^{\circ} \mathrm{C}$. A three-electrode cell was used comprising a 1 mm Pt-disk working electrode, a Pt-wire auxiliary electrode, and an aqueous saturated calomel (SCE) reference electrode. Mass spectra were recorded by the 'Service de Spectroscopie de Masse' of Paul Sabatier University using ESI UPLC XEVO G2 QTOF and UHPLC 3000 DIONEX or EI $\left(\mathrm{NH}_{3}\right)$ DSQ Thermo Fisher Scientific or ESI QTRAP 2000 (Applied Biosystems) and API-365 (Perkin Elmer Sciex). ${ }^{1} \mathrm{H}-\mathrm{NMR}$ and ${ }^{13} \mathrm{C}-\mathrm{NMR}$ spectra were measured on Bruker Avance $500 \mathrm{MHz}$ CryoSonde and Bruker Avance $300 \mathrm{MHz}$ equipments in $\mathrm{CD}_{2} \mathrm{Cl}_{2}$ and $\mathrm{CDCl}_{3}$ at $20^{\circ} \mathrm{C}\left(\mathrm{CD}_{2} \mathrm{Cl}_{2}\right.$ at $\delta \mathrm{H}: 5.32, \delta \mathrm{C}: 54.0, \mathrm{CDCl}_{3}$ at $\delta \mathrm{H}$ : 7.26, $\delta \mathrm{C}: 77.16 \mathrm{ppm}) .{ }^{1} \mathrm{H}$ and ${ }^{13} \mathrm{C}$ chemical shifts are reported in parts per million (ppm) relative to $\mathrm{Me}_{4} \mathrm{Si}$ as reference standard. Electronic circular dichroism, ECD, (in $\mathrm{M}^{-1} \mathrm{~cm}^{-1}$ ) was measured on a Jasco J-815 Circular Dichroism Spectrometer (IFR140 facility - Biosit - Université de Rennes 1).

\section{Optical resolutions}

Supercritical fluid chromatography (SFC) has become a mainstream technology for chiral separations based on its higher efficiency, throughput, and wide applicability. Isocratic method development was developed on the ACQUITY UltraPerformance Convergence Chromatography System ${ }^{\mathrm{TM}}\left(\mathrm{UPC}^{2}\right)^{\circledR}$ from Waters. Chiral separations were run on Preparative-scale SFC 80q system from Waters using a Chiralpack IC $5 \mu \mathrm{m}(20$ x 250) mm column and a 2489 UV detector from Waters monitoring at $367 \mathrm{~nm}$ for $\mathbf{1 , 2}$ and 4; $352 \mathrm{~nm}$ for 3, and $245 \mathrm{~nm}$ for $\mathbf{5}$. The working temperature and pressure of the column were $40^{\circ} \mathrm{C}$ and 100 bar, respectively. Purification of chiral compounds by SFC typically utilizes isocratic method 
conditions and stacked injections for optimal collection efficiency. This process is called volume overloading as opposed to concentration overloading. ${ }^{35}$ In order to increase the productivity, the stacked injections gave the possibility to perform the second injection before the end of the elution of the second enantiomer. All compounds were eluted in isocratic mode using a $40 \mathrm{~mL} / \mathrm{min}$ flow of a mixture of $\mathrm{CO}_{2} / \mathrm{MeOH}(8 / 2)$ except for 3, which was eluted with a mixture of $\mathrm{CO}_{2} / \mathrm{CH}_{3} \mathrm{CN}(8 / 2)$. For 1 , a sample of $400 \mathrm{mg}$ was dissolved in $6 \mathrm{~mL}$ of methanol, concentration of the injected quantity was $66.6 \mathrm{mg} / \mathrm{mL}$. The volume of injection was $0.5 \mathrm{~mL}$ which generated a mass of $33 \mathrm{mg}$ per injection. Here, 9 injections of $33 \mathrm{mg}$ or $297 \mathrm{mg}$ were resolved in less than $50 \mathrm{~min}$ (see Figure S1c in the Supporting Information, SI). For 2, a sample of $200 \mathrm{mg}$ was dissolved in $8 \mathrm{~mL}$ of acetonitrile, concentration of the injected quantity was $25 \mathrm{mg} / \mathrm{mL}$. The volume of injection was $0.5 \mathrm{~mL}$ which generated a mass of 12.5 mg per injection. Here, 6 injections of $12.5 \mathrm{mg}$ or $75 \mathrm{mg}$ were resolved in less than $35 \mathrm{~min}$ (Figure S1h, SI). For 3, compound was eluted in isocratic mode using a $40 \mathrm{~mL} / \mathrm{min}$ flow of a mixture of $\mathrm{CO}_{2} / \mathrm{CH}_{3} \mathrm{CN}(8 / 2)$. A sample of $200 \mathrm{mg}$ was dissolved in $20 \mathrm{~mL}$ of acetonitrile; concentration of the injected quantity was $10 \mathrm{mg} / \mathrm{mL}$. The volume of injection was $1 \mathrm{~mL}$ which generated a mass of $10 \mathrm{mg}$ per injection. Here, 13 injections of $10 \mathrm{mg}$ or $130 \mathrm{mg}$ were made in less than 104 min (Figure S1m, SI). For each fraction of 3, a second purification in the same conditions was carried out to improve the purity of each of the peaks. This separation was more difficult than the others. For 4, a sample of $200 \mathrm{mg}$ was dissolved in 5 $\mathrm{mL}$ of methanol, concentration of the injected quantity was $40 \mathrm{mg} / \mathrm{mL}$. The volume of injection was $0.5 \mathrm{~mL}$ which generated a mass of $20 \mathrm{mg}$ per injection. Here, 6 injections of 20 $\mathrm{mg}$ or $120 \mathrm{mg}$ were resolved in less than $35 \mathrm{~min}$ (Figure S1r, SI). For 5, a sample of $200 \mathrm{mg}$ was dissolved in $5 \mathrm{~mL}$ of heptane, concentration of the injected quantity was $40 \mathrm{mg} / \mathrm{mL}$. The volume of injection was $0.5 \mathrm{~mL}$ which generated a mass of $20 \mathrm{mg}$ per injection. Here, 9 injections of $20 \mathrm{mg}$ or $180 \mathrm{mg}$ were resolved in less than $35 \mathrm{~min}$ (Figure S1w, SI). Post- 
enantioseparation analyses were determined on an ACQUITY UPC ${ }^{2}$ System from Waters using a Chiralpack IC $3 \mu \mathrm{m}(4.6$ x $100 \mathrm{~mm})$ column eluted with supercritical (sc) $\mathrm{CO}_{2} / \mathrm{CH}_{3} \mathrm{OH}$ under gradient conditions. The detection was performed with an UV detector coupled to a simple quadrupole mass detector from Waters. The flow was $1 \mathrm{~mL} / \mathrm{min}$. Starting mobile phase composition of the gradient was $100 \% \mathrm{CO}_{2}$ and final mobile phase composition was a mixture of $\mathrm{sc} \mathrm{CO}_{2}$ and $\mathrm{CH}_{3} \mathrm{OH}(70 / 30)$. The eluent composition was changing during 5 min. The working temperature and pressure of the column were $40^{\circ} \mathrm{C}$ and 120 bar. Purities very close to $100 \%$ were obtained in all cases. All the analytical SFC files before and after the chiral resolutions and the preparative SFC files are shown in the SI (part S1).

\section{X-ray diffraction studies}

Data for X-ray single-crystal structure determination were collected with a Nonius KappaCCD automatic X-ray single-crystal diffractometer, using Mo $\mathrm{K} \alpha$ radiation, for which a graphite monochromator was applied. Intensities were measured using an Apex2 detector and at a temperature of $293 \mathrm{~K}$. The crystallographic cell was found using Apex 2 software. $^{36}$ The point group determination was followed by the determination of the position of all nonhydrogen atoms by direct methods using SIR $2011^{37}$ and refined in the WinGX software package $^{38}$ using SHELX-97. ${ }^{39}$ Absorption corrections were performed using the SADABS program. ${ }^{36}$ All non-hydrogen atoms were refined isotropically and then anisotropically. All hydrogen atoms were placed geometrically and treated as riding in geometrically optimized positions. CCDC 1423363 and CCDC 1476307 contain the supplementary crystallographic data for this paper. These data can be obtained free of charge from the Cambridge Crystallographic Data Centre via www.ccdc.cam.ac.uk/data_request/cif 
Table 1. Crystal and refinement data for $\mathbf{1}$ and $\mathbf{5}$.

\begin{tabular}{|c|c|c|}
\hline Empirical Formula & $\mathrm{C}_{27} \mathrm{H}_{45} \mathrm{O}_{6} \mathrm{Co}[5]$ & $\mathrm{C}_{27} \mathrm{H}_{45} \mathrm{O}_{6} \mathrm{Ru}[\mathbf{1}]$ \\
\hline Formula Weight & 522.54 & 566.7 \\
\hline Wavelength $(\AA)$ & 0.71073 & 0.71073 \\
\hline Crystal System & Triclinic & Triclinic \\
\hline Space Group & P-1 & P-1 \\
\hline Unit cell dimensions & & \\
\hline$a(\AA)$ & 7.894 & 7.874 \\
\hline$b(\AA)$ & 12.073 & 12.144 \\
\hline$c(\AA)$ & 15.577 & 15.678 \\
\hline$\alpha\left(^{\circ}\right)$ & 83.38 & 83.19 \\
\hline$\beta\left(^{\circ}\right)$ & 76.53 & 76.27 \\
\hline$\gamma\left({ }^{\circ}\right)$ & 77.64 & 78.58 \\
\hline Volume $\left(\AA^{3}\right)$ & 1406.9 & 1423.4 \\
\hline $\mathrm{Z}$ & 2 & 2 \\
\hline$D_{\text {calc }}\left(\mathrm{Mg} / \mathrm{m}^{3}\right)$ & 1.234 & 1.322 \\
\hline$\mu(\operatorname{MoK} \alpha)\left(\mathrm{mm}^{-1}\right)$ & 0.646 & 0.586 \\
\hline$F(000)$ & 560 & 598 \\
\hline Crystal size (mm) & $0.5 * 1.2 * 1.3$ & $0.1 * 0.6 * 1$ \\
\hline $\begin{array}{l}\theta \text { Range for data } \\
\text { collection }\left(^{\circ}\right)\end{array}$ & $1.347-28.386$ & $1.716-28.877$ \\
\hline Limiting indices & $-10<\mathrm{h}<10$ & $-10<h<10$ \\
\hline & $-16<\mathrm{k}<16$ & $-16<k<16$ \\
\hline & $-20<1<20$ & $-21<1<21$ \\
\hline $\begin{array}{c}\text { Reflections } \\
\text { observed/unique }\end{array}$ & $45050 / 7053$ & $75489 / 7434$ \\
\hline Completeness to $\theta(\%)$ & 99.8 & 99.3 \\
\hline Refinement method & \multicolumn{2}{|c|}{ Full matrix least squares on $\mathrm{F}^{2}$} \\
\hline Data/parameters & $7053 / 316$ & $6232 / 307$ \\
\hline Goodness of fit on $\mathrm{F}^{2}$ & 1.062 & 1.087 \\
\hline \multirow[t]{2}{*}{ Final $\mathrm{R}$ indices } & $\mathrm{R}_{1}=0.0564$ & $\mathrm{R}_{1}=0.0401$ \\
\hline & $\mathrm{wR}_{2}=0.1773$ & $\mathrm{wR}_{2}=0.1304$ \\
\hline $\begin{array}{l}\text { Largest difference in } \\
\text { peak and hole }\left(\mathrm{e} \AA^{-3}\right)\end{array}$ & 1.02 and -0.75 & 0.84 and -0.86 \\
\hline
\end{tabular}

\section{Ligands syntheses}

A mixture of the corresponding 1-alkyliodide $(32.0 \mathrm{mmol})$ and sodium pentane-2,4-dionate (3.20 g, $26.0 \mathrm{mmol})$ in 2-butanone $(50 \mathrm{~mL})$ was heated under reflux for $72 \mathrm{~h}$. Then, the solvent was evaporated and diethyl ether was added. The solution was filtrated off, extracted twice with brine and dried with magnesium sulfate. After evaporation of the solvent, the product was purified by chromatography in silica gel using dichloromethane as eluent. 
3-butylpentane-2,4-dione (Buacac): yellowish oil (2.20 g, 54\%). ${ }^{1} \mathrm{H}-\mathrm{NMR}(300 \mathrm{MHz}$, $\mathrm{CD}_{2} \mathrm{Cl}_{2}$ ): keto (70\%): 3.60 (t, J: $\left.7.2 \mathrm{~Hz}, 1 \mathrm{H}\right), 2.14(\mathrm{~s}, 6 \mathrm{H}), 1.83-1.76(\mathrm{~m}, 2 \mathrm{H}), 1.40-1.14(\mathrm{~m}$, 4H), 0.88 (t, J: $7.2 \mathrm{~Hz}, 3 \mathrm{H})$; enol (30\%): 16.69 (s, 1H), $2.20(\mathrm{~m}, 2 \mathrm{H}), 2.11(\mathrm{~s}, 6 \mathrm{H}), 1.40-1.14$ (m, 4H), 0.93 (t, J: $6.9 \mathrm{~Hz}, 3 \mathrm{H}) .{ }^{13} \mathrm{C}-\mathrm{NMR}\left(300 \mathrm{MHz}, \mathrm{CD}_{2} \mathrm{Cl}_{2}\right)$ : keto: 204.96, 69.06, 30.28, 29.62, 28.51, 23.12, 14.11; enol: 191.57, 111.16, 33.33, 27.75, 23.22, 23.19, 14.21. Chemical Ionization-MS $\left(\mathrm{NH}_{3}\right) 157[\mathrm{M}+\mathrm{H}]^{+}, 174\left[\mathrm{M}+\mathrm{NH}_{4}\right]^{+}$.

3-octylpentane-2,4-dione (Oacac): yellowish oil (2.44 g, 44\%). ${ }^{1} \mathrm{H}-\mathrm{NMR}(300 \mathrm{MHz}$, $\mathrm{CD}_{2} \mathrm{Cl}_{2}$ ): keto (70\%): $3.58(\mathrm{t}, J: 7.2 \mathrm{~Hz}, 1 \mathrm{H}), 2.13(\mathrm{~s}, 6 \mathrm{H}), 1.81-1.74(\mathrm{~m}, 2 \mathrm{H}), 1.25(\mathrm{~m}, 12 \mathrm{H})$, $0.86(\mathrm{t}, J: 7.2 \mathrm{~Hz}, 3 \mathrm{H})$; enol (30\%) $16.69(\mathrm{~s}, 1 \mathrm{H}), 2.21-2.16(\mathrm{~m}, 2 \mathrm{H}), 2.10(\mathrm{~s}, 6 \mathrm{H}), 1.25(\mathrm{~m}$, 12H), 0.87 (t, J: $7.2 \mathrm{~Hz}, 3 \mathrm{H}) .{ }^{13} \mathrm{C}-\mathrm{NMR}\left(300 \mathrm{MHz}, \mathrm{CD}_{2} \mathrm{Cl}_{2}\right.$ ): keto: 204.97, 69.12, 32.40, 30.04, 29.85, 29.83, 29.76, 29.63, 28.83, 23.22, 14.43; enol: 191.57, 111.22, 32.44, 31.18, 30.17, 29.97, 29.89, 28.06, 23.22, 23.22, 14.43. Chemical Ionization-MS $\left(\mathrm{NH}_{3}\right) 213[\mathrm{M}+\mathrm{H}]^{+}$, $230\left[\mathrm{M}+\mathrm{NH}_{4}\right]^{+}$.

\section{Complexes syntheses}

Synthesis of $\mathrm{Ru}(\text { Buacac })_{3}$ (1) and $\mathrm{Ru}(\mathrm{Oacac})_{3}$ (2): Ruthenium(III) chloride hexahydrate $(0.61 \mathrm{~g}, 2.5 \mathrm{mmol})$, the corresponding 3-alkylpentane-2,4-dione $(7.5 \mathrm{mmol})$ and urea $(0.45 \mathrm{~g}$, $7.5 \mathrm{mmol})$ were placed in a purged flask and dissolved in $40 \mathrm{~mL}$ of a methanol/water $(1 / 1)$ mixture. The solution was refluxed under argon for $24 \mathrm{~h}$. Then, the system was allowed to warm up to room temperature and extracted with dichloromethane and brine. The organic solution was dried over magnesium sulfate and evaporated. The product was purified by chromatography in silica gel using dichloromethane as eluent. Crystals of 1 suitable for single-crystal X-ray diffraction were obtained from a concentrated solution of the complex in hexane at $-20^{\circ} \mathrm{C}$.

$R u(\text { Buacac) })_{3}$ (1): red lake (0.46 g, 32\%). ${ }^{1} \mathrm{H}-\mathrm{NMR}\left(500 \mathrm{MHz}, \mathrm{CD}_{2} \mathrm{Cl}_{2}\right): 29.48(\mathrm{~s}, 1 \mathrm{H})$, $28.93(\mathrm{~s}, 1 \mathrm{H}), 1.82(\mathrm{~s}, 2 \mathrm{H}), 1.75(\mathrm{~s}, 3 \mathrm{H}),-0.14(\mathrm{~s}, 1 \mathrm{H}),-1.10(\mathrm{~s}, 1 \mathrm{H}),-9.85$ (s, 6H). IR (KBr, 
$\left.\mathrm{cm}^{-1}\right): 2960 \mathrm{~m}, 2927 \mathrm{~m}, 2876 \mathrm{w}, 2855 \mathrm{w} v(\mathrm{C}-\mathrm{H}), 1541 v(\mathrm{C}=\mathrm{O})$ and $v(\mathrm{C}=\mathrm{C})$. TOF-MS ES ${ }^{+}: 567$ $[\mathrm{M}+\mathrm{H}]^{+}, 590[\mathrm{M}+\mathrm{Na}]^{+}, 1157[2 \mathrm{M}+\mathrm{Na}]^{+}$.

$R u(O a c a c)_{3}$ (2): red lake (0.47 g, 26\%). ${ }^{1} \mathrm{H}-\mathrm{NMR}\left(500 \mathrm{MHz}, \mathrm{CD}_{2} \mathrm{Cl}_{2}\right): 29.29$ (s, 1H), 28.99 $(\mathrm{s}, 1 \mathrm{H}), 1.84(\mathrm{~s}, 2 \mathrm{H}), 1.72(\mathrm{~s}, 2 \mathrm{H}), 1.34(\mathrm{~s}, 6 \mathrm{H}), 0.91(3 \mathrm{H}),-0.29(\mathrm{~s}, 1 \mathrm{H}),-1.15(\mathrm{~s}, 1 \mathrm{H}),-9.80$ (s, 6H). IR (KBr, cm $\left.{ }^{-1}\right): 2956 \mathrm{~m}, 2924 \mathrm{~m}, 2866,2854 \mathrm{w} v(\mathrm{C}-\mathrm{H}), 1542 v(\mathrm{C}=\mathrm{O})$ and $v(\mathrm{C}=\mathrm{C})$. TOF-MS ES ${ }^{+}: 736[\mathrm{M}+\mathrm{H}]^{+}, 759[\mathrm{M}+\mathrm{Na}]^{+}, 1494[2 \mathrm{M}+\mathrm{Na}]^{+}$.

Synthesis of $\mathrm{Cr}(\mathrm{Buacac})_{3}(3)$ and $\mathrm{Cr}(\mathrm{Oacac})_{3}$ (4): The procedure was adapted from the literature. ${ }^{6,8}$ A solution of the corresponding 3-alkylpentane-2,4-dione (7.5 mmol), chromium chloride hexahydrate $(0.67 \mathrm{~g}, 2.5 \mathrm{mmol})$, urea $(0.45 \mathrm{~g}, 2.5 \mathrm{mmol})$ in a $50 \mathrm{~mL}$ mixture of water/ethanol (1/1) was heated under reflux for $24 \mathrm{~h}$. The system was allowed to warm up to room temperature and extracted with dichloromethane and brine. The organic solution was dried over magnesium sulfate and evaporated. The product was purified by chromatography in silica gel using dichloromethane as eluent.

$\mathrm{Cr}(\text { Buacac })_{3}$ (3): green oil $(0.20 \mathrm{~g}, 18 \%)$. The ${ }^{1} \mathrm{H}$ NMR spectrum could not be interpreted. IR $\left(\mathrm{KBr}, \mathrm{cm}^{-1}\right): 2957 \mathrm{~m}, 2930 \mathrm{~m}, 2866 \mathrm{w}, 2848 \mathrm{w} v(\mathrm{C}-\mathrm{H}), 1563 v(\mathrm{C}=\mathrm{O})$. TOF-MS ES ${ }^{+}: 518$ $[\mathrm{M}+\mathrm{H}]^{+}, 540[\mathrm{M}+\mathrm{Na}]^{+}, 1058[2 \mathrm{M}+\mathrm{Na}]^{+}$.

$\mathrm{Cr}(\mathrm{Oacac})_{3}$ (4): green oil $(0.44 \mathrm{~g}, 25 \%)$. The ${ }^{1} \mathrm{H}$ NMR spectrum could not be interpreted. IR $\left(\mathrm{KBr}, \mathrm{cm}^{-1}\right): 2956 \mathrm{~m}, 2924 \mathrm{~m}, 2854 \mathrm{~m} v(\mathrm{C}-\mathrm{H}), 1568 v(\mathrm{C}=\mathrm{O})$. TOF-MS ES $\mathrm{C}^{+}: 687[\mathrm{M}+\mathrm{H}]^{+}$, $709[\mathrm{M}+\mathrm{Na}]^{+}, 1394[2 \mathrm{M}+\mathrm{Na}]^{+}$.

Synthesis of $\mathrm{Co}(\text { Buacac })_{3}$ (5): The procedure was adapted from the literature. ${ }^{40} 3$ Butylpentane-2,4-dione $(1.00 \mathrm{~g}, 6.40 \mathrm{mmol})$ was suspended in $60 \mathrm{~mL}$ of a water/ethanol $(5 / 1)$ mixture, and treated with a $0.2 \mathrm{M}$ solution of $\mathrm{NaOH}(32 \mathrm{~mL})$. A solution of sodium hexanitritocobaltate(III) $(0.86 \mathrm{~g}, 2.13 \mathrm{mmol})$ in $30 \mathrm{~mL}$ of water was then slowly added and the reaction mixture was stirred at room temperature for $5 \mathrm{~h}$. The residue was extracted with dichloromethane and brine, dried over magnesium sulfate and evaporated. The product was 
purified by chromatography in silica gel using a mixture of dichloromethane/hexane (1/1) as eluent.

$\mathrm{Co}(\text { Buacac })_{3}$ (5): green lake $(0.14 \mathrm{~g}, 13 \%) .{ }^{1} \mathrm{H}-\mathrm{NMR}\left(300 \mathrm{MHz}, \mathrm{CD}_{2} \mathrm{Cl}_{2}\right): 2.30(\mathrm{t}, 2 \mathrm{H})$, $2.19(\mathrm{~s}, 6 \mathrm{H}), 1.37-1.35(\mathrm{~m}, 4 \mathrm{H}), 0.93(\mathrm{t}, 3 \mathrm{H}) .{ }^{13} \mathrm{C}-\mathrm{NMR}\left(500 \mathrm{MHz}, \mathrm{CDCl}_{3}\right): 187.93,107.28$, 33.5, 29.47, 25.43, 22.63, 14.21. IR $\left(\mathrm{KBr}, \mathrm{cm}^{-1}\right): 2960 \mathrm{~m}, 2930 \mathrm{~m}, 2875 \mathrm{w}, 2857 \mathrm{w} v(\mathrm{C}-\mathrm{H})$, 1568s $v(\mathrm{C}=\mathrm{O})$ and $v(\mathrm{C}=\mathrm{C})$. TOF-MS ES ${ }^{+}: 525[\mathrm{M}+\mathrm{H}]^{+}, 547[\mathrm{M}+\mathrm{Na}]^{+}, 563[\mathrm{M}+\mathrm{K}]^{+}, 1071$ $[2 \mathrm{M}+\mathrm{Na}]^{+}$.

\section{Electrochemistry / Spectroelectrochemistry}

Cyclic voltammograms were obtained with an Autolab system (PGSTAT100) in $\mathrm{CH}_{2} \mathrm{Cl}_{2}$ (0.1 $\mathrm{M} \mathrm{TBAPF}_{6}$, as supporting electrolyte) at $25^{\circ} \mathrm{C}$. A three electrode cell was used comprising a $1 \mathrm{~mm}$ Pt-disk working electrode, a Pt-wire auxiliary electrode, and an aqueous saturated calomel (SCE) reference electrode. UV/Vis/NIR spectroelectrochemistry (SEC) experiments were performed at $20^{\circ} \mathrm{C}$, under argon, with a home-built Optically Transparent Thin-Layer Electrosynthetic (OTTLE) cell, using a Varian CARY 5000 spectrometer and an EG\&G PAR model 362 potentiostat. A Pt mesh was used as the working electrode, a Pt wire as the counter electrode, and a Pt wire as a pseudo-reference electrode. The electrodes were arranged in the cell such that the Pt mesh was in the optical path of the quartz cell. The anhydrous freeze-pump-thaw degassed sample-electrolyte solution $\left(0.2 \mathrm{M} \mathrm{TBAPF}_{6}\right)$ was cannula-transferred under argon into the cell previously thoroughly deoxygenated. Stable isobestic points were observed during oxidation or reduction. In every case re-reduced or reoxidized samples displayed in the spectral region of interest no features other than those of the parent material. ECD experiments were performed in similar conditions using a modified cell with KBr windows, on a Jasco J-815 Circular Dichroism Spectrometer (IFR140 facility Université de Rennes 1). 


\section{Computational details}

To obtain insight into electronic structure and spectroscopic features of the experimentally studied complexes 1-5, Kohn-Sham density functional theory (KS DFT) geometry optimizations and time-dependent KS (TDKS, TDDFT) response calculations were performed for a series of $\Lambda-\mathrm{M}(\text { Meacac })_{3}(\mathrm{M}=\mathrm{Ru}, \mathrm{Cr}$, Co; Meacac $=3$-methylpentane-2,4dione) species (Figure 3). For comparison, some computations were also carried out for the corresponding $\Lambda-\mathrm{M}(\mathrm{acac})_{3}(\mathrm{M}=\mathrm{Ru}, \mathrm{Cr}, \mathrm{Co}$; acac = pentane-2,4-dione $)$ complexes, for which stability of different spin electronic configurations was also examined. A high similarity between simulated spectral envelopes for $\mathrm{M}(\mathrm{Meacac})_{3}$ and $\mathrm{M}(\mathrm{acac})_{3}$ confirms that the metal$(\mathrm{acac})_{3}$ core is predominantly responsible for the observed spectral features (note also high resemblance of experimental ECD spectra of 1-2 / 3-4 and the parent $\mathrm{Ru}(\mathrm{acac})_{3} / \mathrm{Cr}(\mathrm{acac})_{3}$ complexes); in some cases the alkyl substituents of acac ligands appear however to slightly affect energetic position and intensity of calculated bands.

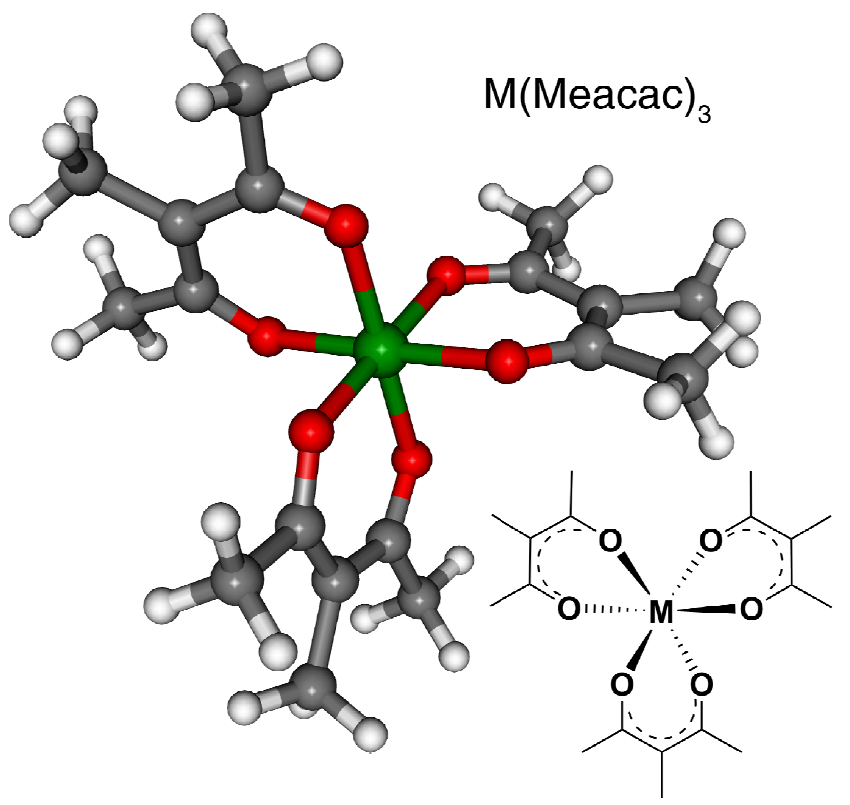

\begin{tabular}{|c|c|c|}
\hline System & $\begin{array}{l}\text { Total spin } \\
\text { number } S\end{array}$ & $\begin{array}{l}\text { Multiplicity } \\
\text { (spin state) }\end{array}$ \\
\hline $\mathrm{Ru}(\text { Meacac })_{3}$ & $1 / 2$ & 2 (doublet) \\
\hline $\operatorname{Ru}(\text { Meacac })_{3}{ }^{o x}$ & 1 & 3 (triplet) \\
\hline $\mathrm{Ru}(\text { Meacac })_{3}^{\text {Red }}$ & 0 & 1 (singlet) \\
\hline $\mathrm{Cr}(\text { Meacac })_{3}$ & $3 / 2$ & 4 (quartet) \\
\hline $\mathrm{Cr}(\text { Meacac })_{3}{ }^{\alpha x}$ & 1 & 3 (triplet) \\
\hline $\mathrm{Co}(\text { Meacac })_{3}$ & 0 & 1 (singlet) \\
\hline $\mathrm{Co}(\text { Meacac })_{3}{ }^{\mathrm{ox}}$ & $1 / 2$ & 2 (doublet) \\
\hline
\end{tabular}

Figure 3. Molecular structure of $\mathrm{M}(\mathrm{Meacac})_{3}$ complex in its $\Lambda$ configuration studied as a model for 1-5 along with spin-state details for particular species considered. 
All calculations were performed with Turbomole 6.6 package, ${ }^{41-43}$ without imposing molecular symmetry. DFT geometry optimizations employed the B3LYP ${ }^{44-46}$ exchangecorrelation functional in its default Turbomole parameterization. TDDFT linear response electronic circular dichroism (ECD) calculations utilized the generalized gradient approximation (GGA) Becke88-Perdew86 (BP) ${ }^{47-49}$ functional along with two commonly used GGA hybrids B3LYP and PBE0 ${ }^{50}$ In all these computations the polarized triple- $\zeta$ valence basis set $\mathrm{TZVP}^{51}$ was employed for all the atoms. Scalar relativistic effects were treated implicitly by the use of a 60 -electron relativistic effective core potential (ECP) in the case of $\mathrm{Ru}^{52}$ and neglected for $\mathrm{Cr}$ and Co. Solvent effects for dichloromethane (DCM, $\varepsilon=$ 8.9) and 1,2-dichloroethane (DCE, $\varepsilon=10.66)$ were included in the calculations via the conductor-like screening model (COSMO) as implemented in Turbomole..$^{53-55}$

The simulated spectra shown are the sums of Gaussian functions centered at the vertical excitation energies and scaled using the calculated rotatory strengths, with a global $\sigma$ parameter of $0.18 \mathrm{eV}$ applied for the root mean square width. ${ }^{56}$ The benchmark ECD calculations whose results are presented in the top panels of Figures S7a-c in the SI covered the 175 (TDDFT BP) and 100 (TDDFT B3LYP and PBE0) lowest allowed excited states for each system. For the analyzed B3LYP DCE spectra of the $\Lambda$-M(Meacac $)_{3}$ complexes the lowest number of excitations calculated extends at least $1 \mathrm{eV}$ beyond the upper frequency cutoff of the experimental spectra to avoid truncation errors in the simulated broadened ECD intensity.

\section{Results and discussion}

\section{Synthesis and characterization}

The ligands Buacac and Oacac (Figure 2) were readily prepared with an approximate yield of $50 \%$ by a 72 -hours refluxing reaction of the corresponding 1 -alkyliodide with sodium pentane-2,4-dionate in 2-butanone. The procedure was analogous to that described in the 
literature for the synthesis of 3-decylpentane-2,4-dione. ${ }^{57}$ An increase of the reaction time did not improve the yield. Direct alkylation of acetylacetone with the corresponding 1alkyliodide in the presence of potassium carbonate also led to the target ligands but the yield was significantly smaller (15\%).

The two chromium complexes $\mathrm{Cr}(\text { Buacac })_{3}(3)$ and $\mathrm{Cr}(\mathrm{Oacac})_{3}(\mathbf{4})$ were prepared by the procedure described by Anzai et al..$^{6-7}$ The yield was $18 \%$ and $25 \%$ for $\mathbf{3}$ and $\mathbf{4}$, respectively. The ruthenium systems 1 and 2 were synthesized with a $32 \%$ and a $26 \%$ yield following a pathway similar to that employed to analogous $\mathrm{Cr}$ compounds. ${ }^{6-7}$ Ruthenium(III) chloride hydrate and the acac-based ligand were heated in the presence of urea under argon atmosphere for 24 hours in a methanol / water mixture of solvents. Neither shorter nor longer time of the reaction improved the yield. The procedure was also examined without argon atmosphere but a blue side-product was obtained together with the complexes $\mathbf{1}$ and $\mathbf{2}$.

The synthesis pathway analogous to that employed in the case of 1-4 did not lead to $\mathbf{5}$. Consequently, an alternative procedure was adapted from the literature to prepare this compound with a $13 \%$ yield. ${ }^{40}$ A solution of sodium hexanitritocobaltate(III) in water was treated at room temperature with Buacac, previously deprotonated with $\mathrm{NaOH}$. Note that the complex 5 revealed very low chemical stability. Furthermore, despite efforts made, this procedure did not give the $\mathrm{Co}(\mathrm{III})-\mathrm{Oacac}$ derivative, resulting in a yellowish product instead.

The ligands and corresponding metal complexes were then fully characterized. The ${ }^{1} \mathrm{H}-$, ${ }^{13} \mathrm{C}$-, and the 2D-NMR $\left(\left({ }^{1} \mathrm{H}_{-}{ }^{1} \mathrm{H}\right)\right.$ COSY, $\left({ }^{1} \mathrm{H}_{-}{ }^{13} \mathrm{C}\right)$ HSQC, and $\left({ }^{1} \mathrm{H}_{-}{ }^{13} \mathrm{C}\right)$ HMBC $)$ were measured either in $\mathrm{CDCl}_{3}$ or $\mathrm{CD}_{2} \mathrm{Cl}_{2}$ solution (see Figures $\mathrm{S} 2 \mathrm{a}-\mathrm{S} 2 \mathrm{~m}$ and $\mathrm{S} 3 \mathrm{a}-\mathrm{S} 3 \mathrm{~m}$ in the $\mathrm{SI}$ ). The numbering scheme employed in the ${ }^{1} \mathrm{H}-\mathrm{NMR}$ assignment is shown in Figure 2. The Buacac and Oacac can exist in solution in the enol and keto forms, which is evidenced by the simultaneous presence of a signal due to the $\mathrm{OH}$ group (position [6]) of the enol tautomer at ca. $16.7 \mathrm{ppm}$ and a signal at ca. $3.6 \mathrm{ppm}$ for the proton in the position [4] for the keto 
tautomer in their ${ }^{1} \mathrm{H}-\mathrm{NMR}$ spectra. The ${ }^{1} \mathrm{H}-\mathrm{NMR}$ spectra of both ligands reveal a similar pattern, consistent with the presence of the diketone as the major form $(>70 \%)$ as evaluated from the intensity ratios of the peaks. We have been able to assign all ${ }^{1} \mathrm{H}-\mathrm{NMR}$ signals to particular ${ }^{1} \mathrm{H}$ nuclei of Buacac and Oacac (Table 2, Figures S2c and S2i in the SI) and their positions remain in an agreement with the bibliographic values. ${ }^{6,8,40}$ In the case of the ${ }^{13} \mathrm{C}$ NMR spectra, all the C nuclei for both ligands have also been assigned (Figures S2f and S21, SI).

The NMR data of the cobalt(III) system 5 were straightforwardly interpreted because of the diamagnetic nature of the complex that gives simple spectra (Table 2 and Figures S3a-S3g in the SI). In this case, no keto-enol equilibrium is possible due to the deprotonation of the ligand in the complex and the observed chemical shifts are comparable to those of the free Buacac ligand showing for example the protons of the position [2] at 1.35-1.37, [3] at 2.30, and [5] at $2.19 \mathrm{ppm}$. The corresponding Buacac ${ }^{1} \mathrm{H}-\mathrm{NMR}$ shifts are respectively 1.14-1.40, 2.20 and $2.11 \mathrm{ppm}$ (enol form). In the case of the paramagnetic ( $\mathrm{S}=1 / 2$, doublet) ruthenium(III) complexes 1 and $\mathbf{2}$ a noticeable displacement and broadening of the ${ }^{1} \mathrm{H}-\mathrm{NMR}$ peaks was however observed, especially significant for the $\mathrm{H}$ nuclei close to the metal center, in line with what has been observed before in similar paramagnetic compounds, ${ }^{58-63}$ and indicating non-innocent behavior of the ligand. Thus, for example, the protons of the position [3] are shifted to ca. $29 \mathrm{ppm}$, and the peak corresponding to the methyl group in the position [5] appears at $-9.85 \mathrm{ppm}$ for $\mathbf{1}$ and at $\mathbf{- 9 . 8 0} \mathrm{ppm}$ for $\mathbf{2}$ (Table 2 and Figures S3h-S3i in the SI) agreeing reasonably well with available calculated data for $\mathrm{Ru}(\mathrm{acac})_{3} \cdot{ }^{62-63}$ Moreover, some of the protons that are equivalent for the ligands become inequivalent for $\mathbf{1}$ and $\mathbf{2}$. For example, the multiplet observed for the $\mathrm{H}$ nuclei in the position [2] at 1.14-1.40 ppm (4H) for Buacac and $1.25 \mathrm{ppm}(12 \mathrm{H})$ for Oacac becomes a set of three singlets at $1.82(2 \mathrm{H}),-0.14(1 \mathrm{H})$ and $1.10(1 \mathrm{H})$ ppm for 1 and a set of five singlets at $1.84(2 \mathrm{H}), 1.72(2 \mathrm{H}), 1.34(6 \mathrm{H}),-0.29(1 \mathrm{H})$, 
and $-1.15(1 \mathrm{H})$ ppm for 2. Similarly, the aforementioned two protons of the $\mathrm{CH}_{2}$ peak in the position [3] become inequivalent giving rise to two singlets at $29.48(1 \mathrm{H})$ and $28.93(1 \mathrm{H})$ ppm for 1 and at $29.29(1 \mathrm{H})$ and $28.99(1 \mathrm{H})$ for 2. Finally, although NMR spectra of highspin $\left(\mathrm{S}=3 / 2\right.$, quartet) $\mathrm{Cr}(\mathrm{acac})_{3}$ complex have been assigned, ${ }^{61}$ the ones for the corresponding acac derivatives $\mathrm{Cr}$ (III) systems $\mathbf{3}$ and $\mathbf{4}$ were found to be too broad to be reliably interpreted.

Table 2. ${ }^{1} \mathrm{H}-\mathrm{NMR}$ chemical shifts (in ppm) measured in $\mathrm{CD}_{2} \mathrm{Cl}_{2}$ solution for the Buacac and Oacac ligands and the corresponding $\mathrm{Ru}(\mathrm{III})$ and $\mathrm{Co}(\mathrm{III})$ complexes. $^{a}$

\begin{tabular}{|c|c|c|c|c|c|c|c|}
\hline \multirow{2}{*}{${ }^{1} \mathrm{H}$} & \multicolumn{2}{|c|}{ Buacac } & \multicolumn{2}{|c|}{ Oacac } & \multirow{2}{*}{$\begin{array}{c}\mathrm{Ru}(\text { Buacac })_{3} \\
\mathbf{1}\end{array}$} & \multirow{2}{*}{$\begin{array}{c}\mathrm{Ru}(\mathrm{Oacac})_{3} \\
\mathbf{2}\end{array}$} & \multirow{2}{*}{$\begin{array}{c}\mathrm{Co}(\text { Buacac })_{3} \\
\mathbf{5}\end{array}$} \\
\hline & keto form & enol form & keto form & enol form & & & \\
\hline [1] & $0.88(\mathrm{t}, 3 \mathrm{H})$ & $0.93(\mathrm{t}, 3 \mathrm{H})$ & $0.86(\mathrm{t}, 3 \mathrm{H})$ & $0.87(\mathrm{t}, 3 \mathrm{H})$ & $1.75(\mathrm{~s}, 3 \mathrm{H})$ & $0.91(\mathrm{~s}, 3 \mathrm{H})$ & $0.93(t, 3 \mathrm{H})$ \\
\hline [2] & \multicolumn{2}{|c|}{$1.14-1.40(\mathrm{~m}, 4 \mathrm{H})$} & \multicolumn{2}{|c|}{$1.25(\mathrm{~m}, 12 \mathrm{H})$} & $\begin{array}{l}1.82(\mathrm{~s}, 2 \mathrm{H}) \\
-0.14(\mathrm{~s}, 1 \mathrm{H}) \\
-1.10(\mathrm{~s}, 1 \mathrm{H})\end{array}$ & $\begin{array}{r}1.84(\mathrm{~s}, 2 \mathrm{H}) \\
1.72(\mathrm{~s}, 2 \mathrm{H}) \\
1.34(\mathrm{~s}, 6 \mathrm{H}) \\
-0.29(\mathrm{~s}, 1 \mathrm{H}) \\
-1.15(\mathrm{~s}, 1 \mathrm{H})\end{array}$ & $1.35-1.37(\mathrm{~m}, 4 \mathrm{H})$ \\
\hline [3] & $\begin{array}{c}1.76-1.83(\mathrm{~m}, \\
2 \mathrm{H})\end{array}$ & $2.20(\mathrm{~m}, 2 \mathrm{H})$ & $\begin{array}{c}1.74-1.81 \\
(\mathrm{~m}, 2 \mathrm{H})\end{array}$ & $\begin{array}{c}2.16-2.21 \\
(\mathrm{~m}, 2 \mathrm{H})\end{array}$ & $\begin{array}{l}29.48(\mathrm{~s}, 1 \mathrm{H}) \\
28.93(\mathrm{~s}, 1 \mathrm{H})\end{array}$ & $\begin{array}{l}29.29(\mathrm{~s}, 1 \mathrm{H}) \\
28.99(\mathrm{~s}, 1 \mathrm{H})\end{array}$ & $2.30(\mathrm{t}, 2 \mathrm{H})$ \\
\hline$[4]$ & $3.60(\mathrm{t}, 1 \mathrm{H})$ & & $3.58(\mathrm{t}, 1 \mathrm{H})$ & & & & \\
\hline$[5]$ & $2.14(\mathrm{~s}, 6 \mathrm{H})$ & $2.11(\mathrm{~s}, 6 \mathrm{H})$ & $2.13(\mathrm{~s}, 6 \mathrm{H})$ & $2.10(\mathrm{~s}, 6 \mathrm{H})$ & $-9.85(\mathrm{~s}, 6 \mathrm{H})$ & $-9.80(\mathrm{~s}, 6 \mathrm{H})$ & $2.19(\mathrm{~s}, 6 \mathrm{H})$ \\
\hline [6] & & $16.69(\mathrm{~s}, 1 \mathrm{H})$ & & $\begin{array}{c}16.69(\mathrm{~s} \\
1 \mathrm{H})\end{array}$ & & & \\
\hline
\end{tabular}

${ }^{a}$ The atoms numbering is depicted in Figure 2. See also Figures S2a-S2m and S3a-S3m in the SI. 
The IR spectra of the complexes 1-5 in KBr (Figures S4a-S4e, SI) exhibit up to four different $v(\mathrm{C}-\mathrm{H})$ aliphatic peaks in the range of $2960-2848 \mathrm{~cm}^{-1}$. Furthermore, they present a broad band ascribed to the $v(\mathrm{C}=\mathrm{O})$ and $v(\mathrm{C}=\mathrm{C})$ modes of the coordinated $\beta$-diketonate ligand at ca. $1540 \mathrm{~cm}^{-1}$ for $\mathbf{1}$ and 2 and at ca. $1565 \mathrm{~cm}^{-1}$ for $\mathbf{3 - 5}$.

\section{Electrochemistry}

Electrochemical studies via cyclic voltammetry (CV) measurements were performed on the solutions of $\mathbf{1 - 5}$ in dichloromethane (DCM) at room temperature (r.t.) using tetrabutylammonium hexafluorophosphate $\left(\mathrm{TBAPF}_{6}, 0.1 \mathrm{M}\right)$ as supporting electrolyte. The cyclic voltammogram of 2, very close to $\mathbf{1}$, presented in Figure 4 and Figure S6a in the SI, revealed the presence of one chemically and electrochemically quasi-reversible reduction $\left(\Delta \mathrm{E}_{\mathrm{p}}=170 \mathrm{mV}\right)$ at $\mathrm{E}^{\circ}=-1.10 \mathrm{~V}$ vs the saturated calomel electrode (SCE), or $-1.56 \mathrm{~V}$ vs $\mathrm{Fc} / \mathrm{Fc}^{+},{ }^{64}$ and one chemically and electrochemically reversible oxidation $\left(\Delta \mathrm{E}_{\mathrm{p}}=70 \mathrm{mV}\right)$ at $\mathrm{E} 1^{\circ}=+0.72 \mathrm{~V}$ (see Table 3 ), or $+0.26 \mathrm{~V}$ vs $\mathrm{Fc} / \mathrm{Fc}^{+}$. These two waves correspond to oneelectron redox processes. It is noteworthy that the redox processes of $\mathbf{2}$ take place at similar potentials as for $\mathrm{Ru}(\mathrm{acac})_{3}{ }^{65}$ For $\mathbf{3}, \mathbf{4}$ and $\mathbf{5}$, only one wave has been observed in the available window with DCM in our experimental setup, i.e. between -2 and $+2 \mathrm{~V}$ (see Figures S6b to S6d in the SI and Table 3). In both cases, the single wave corresponds to a chemically and electrochemically reversible oxidation process. We note in passing that for $\operatorname{Cr}(\mathrm{acac})_{3}$ a chemically and electrochemically irreversible $\mathrm{Cr}^{\mathrm{III}} / \mathrm{Cr}^{\mathrm{IV}}$ oxidation has been also recently reported. $^{66}$ 


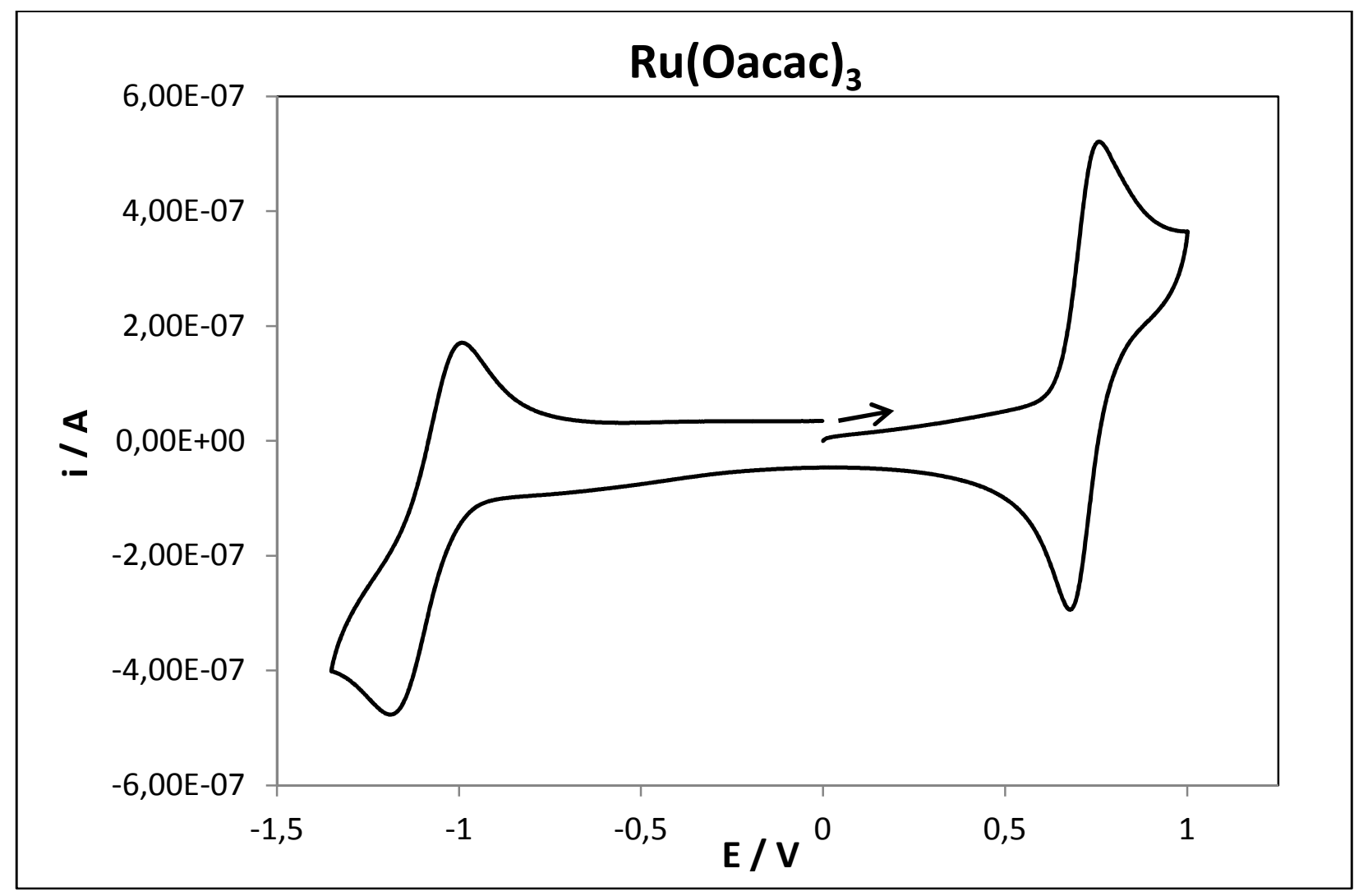

Figure 4. Cyclic voltammogram of $2\left(\mathrm{DCM}, 0.1 \mathrm{M} \mathrm{TBAPF}_{6}\right.$, r.t.) vs $\mathrm{SCE}$ at a scan rate of 0.1 $\mathrm{V} / \mathrm{s}$.

Table 3. Electrochemical data of complexes 1-5. ${ }^{a}$

\begin{tabular}{|c|c|c|}
\hline \multirow{2}{*}{ System } & $\begin{array}{c}\mathrm{E}_{1 / 2}\left(\Delta \mathrm{E}_{\mathrm{p}}\right)[\mathrm{V}] \\
\mathrm{M}^{\mathrm{II}} / \mathrm{M}^{\mathrm{III}}\end{array}$ & $\begin{array}{c}\mathrm{E}_{1 / 2}\left(\Delta \mathrm{E}_{\mathrm{p}}\right)[\mathrm{V}] \\
\mathrm{M}^{\mathrm{III}} / \mathrm{M}^{\mathrm{IV}}\end{array}$ \\
\hline $\mathbf{1}$ & $-1.11(0.17)$ & $0.70(0.09)$ \\
$\mathbf{2}$ & $-1.10(0.17)$ & $0.72(0.07)$ \\
$\mathbf{3}$ & - & $1.18(0.11)$ \\
$\mathbf{4}$ & - & $1.19(0.08)$ \\
$\mathbf{5}$ & - & $1.29(0.07)$ \\
\hline
\end{tabular}

${ }^{a}$ Measurements in DCM, 0.1 M TBAPF 6 at r.t. Potentials vs SCE, $0.1 \mathrm{~V} / \mathrm{s}$. 


\section{X-ray studies}
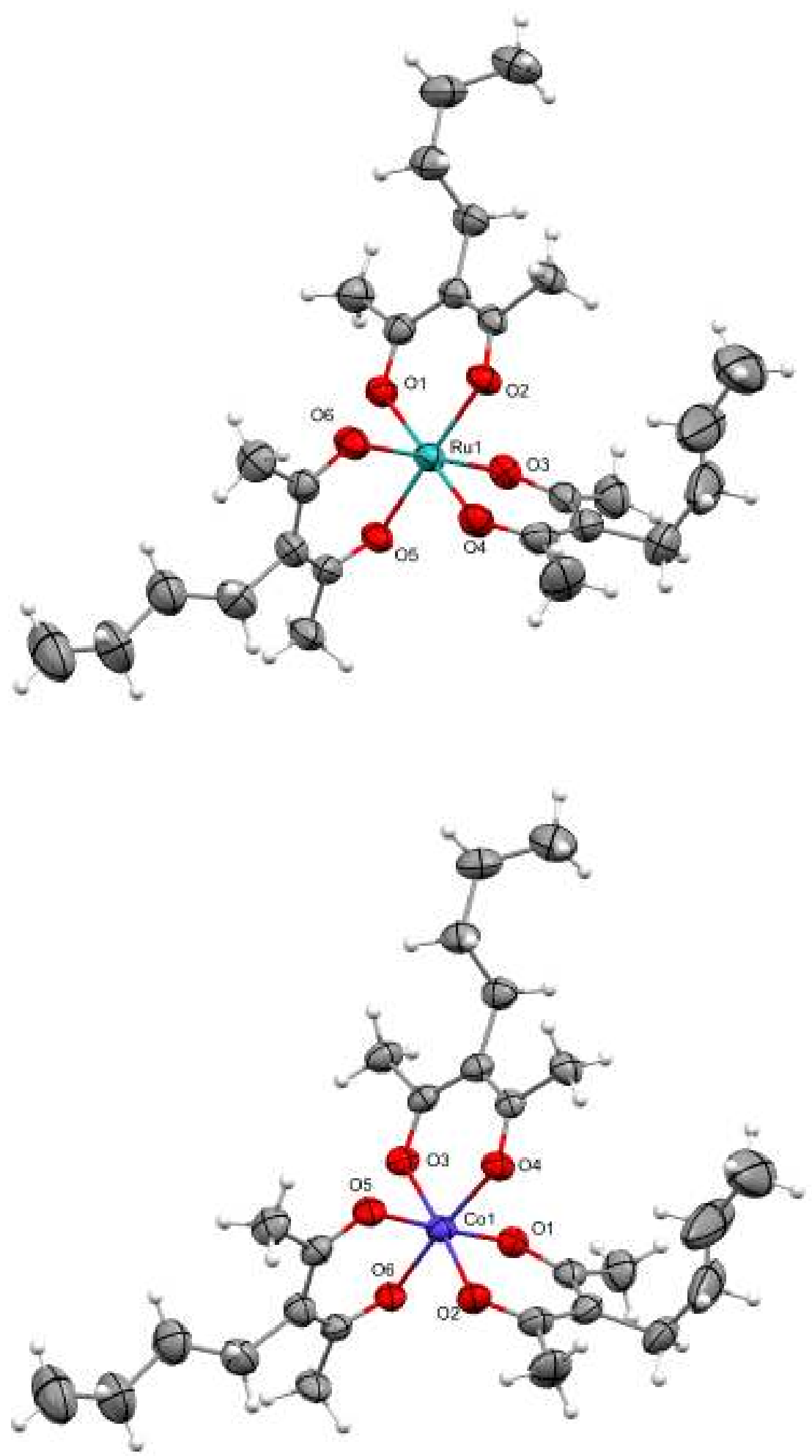

Figure 5. Crystal structure of 1 (top) and 5 (bottom) with thermal ellipsoids at 50\% probability. 
Crystals of $\mathbf{1}$ and $\mathbf{5}$ suitable for single crystal X-ray diffraction were obtained by slow evaporation of a concentrated solution in hexane and a mixture of cyclohexane/dichloromethane $(50 / 50)$, respectively. The same procedure was attempted for 2-4 using hexane and other organic solvents, however unsuccessfully. Crystal structure and refinement data for $\mathbf{1}$ and $\mathbf{5}$ are given in Table 1 and selected bond distances and angles are listed in Tables S5a-S5d in the SI. The representative views are shown in Figure 5. Both 1 and 5 crystallize in the $P-1$ space group. The metal center is coordinated to six oxygen atoms of three chelate Buacac ligands in an octahedral arrangement. The Ru-O distances for $\mathbf{1}$ are in the range of 1.978(1)-2.013(2) $\AA$, consistently with values reported in the literature for the same type of compounds. ${ }^{27,60,67}$ Similarly, the Co-O distances for $\mathbf{5}$ are in the range of 1.870(2)-1.882(2) $\AA$ in good agreement with values reported in the literature for similar compounds. $^{40,68}$ For both compounds, unusual atomic displacement parameters were observed on one of the butyl chains of the Buacac ligand. When looking at the packing of the molecules within the crystal, it appears that a large void is accessible to this chain, leading to larger vibration of the chain, thus explaining the large anisotropic displacement parameters observed. The two other butyl chains of the molecule do not show such degree of freedom due to the presence of intermolecular short contacts or hydrogen bonds with neighboring atoms, as shown in Figures S5e and S5f in the SI.

\section{Electronic circular dichroism (ECD) measurements}

The chiroptical properties, especially electronic and vibrational circular dichroism, of tris( $\beta$-diketonato) transition metal complexes of general formula $\mathrm{M}(\mathrm{acac})_{3}$ with $\mathrm{M}$ including $\mathrm{Ru}$, $\mathrm{Co}, \mathrm{Cr}$, Ir have been extensively studied since they represent a class of chiral $D_{3}$-symmetric systems with a rigid helical structure and $\Delta / \Lambda$ stereoisomerism, enabling unambiguous assignment of their AC. ${ }^{33,69}$ 
The ECD spectra of $\Delta-\Lambda$ enantiomeric pairs of $\mathbf{1 - 5}$ were thus measured in DCM at concentrations between $1-3 \cdot 10^{-3} \mathrm{M}$. The resulting mirror-image spectra of $\Delta-/ \Lambda-1-5$ are displayed in Figure 6. As it can be seen, the $\mathrm{Ru}(\mathrm{III})$ complexes $\mathrm{Ru}(\mathrm{Buacac})_{3}$ (1) and $\mathrm{Ru}(\mathrm{Oacac})_{3}$ (2) display very similar ECD envelopes that closely resemble that of $\mathrm{Ru}(\mathrm{acac})_{3}$ previously reported by Sato et al. ${ }^{33}$ Such similarity can also be observed for Cr(III) systems 3, 4 and $\mathrm{Cr}(\mathrm{acac})_{3}{ }^{33}$ This indicates that the metal-(acac) $)_{3}$ core is predominantly responsible for the observed spectral features. Utilizing the observed resemblance of ECD for $\mathrm{Ru}$ and $\mathrm{Cr}$ complexes studied here and for $\mathrm{Ru}(\mathrm{acac})_{3}$ and $\mathrm{Cr}(\mathrm{acac})_{3}$ of established absolute configuration, the $\Delta / \Lambda \mathrm{AC}$ can be assigned to $\mathbf{1}$ and $\mathbf{2}$ having positive / negative ECD absorption bands at 280 and $450 \mathrm{~nm}$, and to 3 and $\mathbf{4}$ having a positive / negative ECD intensity at $300 \mathrm{~nm}$. Likewise, a comparison of the ECD spectrum of Co(III) complex $\mathbf{5}$ with the ones of $\mathrm{Co}(\mathrm{acac})_{3}$ enantiomers reported in the literature ${ }^{33}$ enabled to assign the $\Delta$ configuration for complex 5 having a negative CD absorption band at $280 \mathrm{~nm}$ (see Figure 6). The ECD spectra of $\mathrm{M}(\text { Meacac })_{3}(\mathrm{M}=\mathrm{Ru}, \mathrm{Cr}, \mathrm{Co})$ complexes as 1-5 models were then calculated with time-dependent DFT (TDDFT) supporting the aforementioned AC assignment (vide infra, Figures S7a-S7c in the SI). 

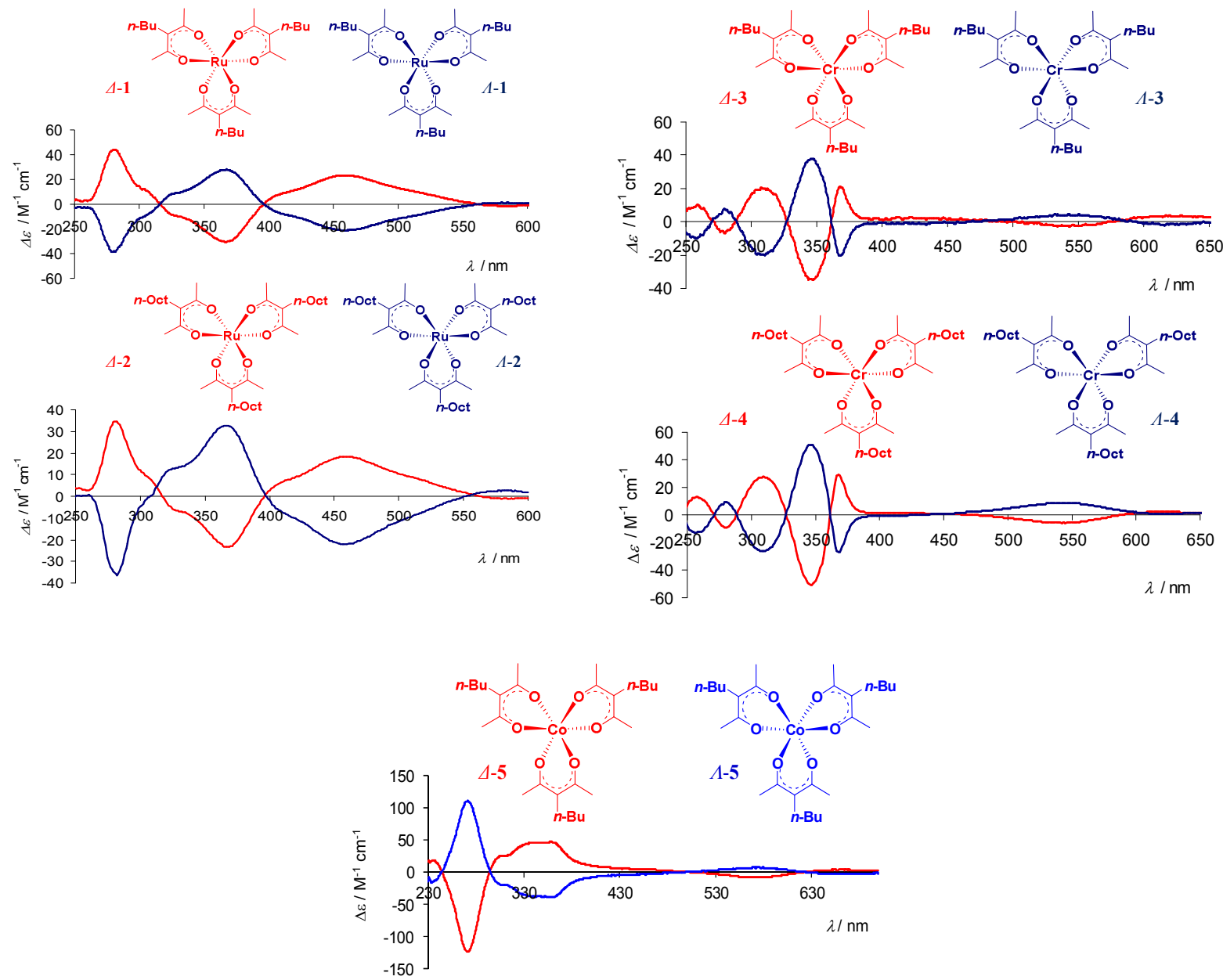

Figure 6. Experimental ECD spectra of $\Delta-/ \Lambda-1, \Delta-/ \Lambda-2, \Delta-/ \Lambda-3, \Delta-/ \Lambda-4$, and $\Delta-/ \Lambda-5$ enantiomeric pairs in DCM.

\section{Spectroelectrochemical behavior and redox chiroptical switching}

We then investigated the capacity of these novel tris( $\beta$-diketonato) $\mathrm{Ru}(\mathrm{III}), \mathrm{Cr}(\mathrm{III})$, and Co(III) complexes to act as redox-triggered chiral switches. Chiroptical switches are multifunctional materials that may be useful for a variety of applications such as in molecular electronics, optical displays, or for telecommunication purposes. ${ }^{70-74}$ Accordingly, in this section, we report on the spectroelectrochemical behavior of 1-5 complexes with 2 and 4 chosen as representatives of $\mathrm{Ru}$ - and $\mathrm{Cr}$-based systems due to their larger mass quantity available and / or higher stability. The experimental results presented have been analyzed and rationalized with the help of time-dependent DFT (TDDFT) response calculations for a series 
of $\Lambda$-M(Meacac $)_{3}(\mathrm{M}=\mathrm{Ru}, \mathrm{Cr}, \mathrm{Co}$; Meacac = 3-methylpentane-2,4-dione $)$ species using B3LYP/TZVP with continuum solvent model for DCM at structures optimized at the same level of theory (see the SI for a full set of calculated data). ${ }^{75-78,79}$

The one-electron oxidation and reduction of 2 into $2^{\mathrm{Ox}}\left(\mathrm{Ru}^{\mathrm{III}} / \mathrm{Ru}^{\mathrm{IV}}\right)$ and $\mathbf{2}^{\mathrm{Red}}\left(\mathrm{Ru} u^{\mathrm{III}} / \mathrm{Ru}^{\mathrm{II}}\right)$, respectively, were monitored by UV-vis/NIR spectroscopy in a transparent thin-layer electrochemical (OTTLE) cell. As presented in Figure 7a, the one-electron oxidation of 2 at 1.2 $\mathrm{V}$ vs Fc/Fc ${ }^{+}$revealed a slight decrease in intensity of the UV-vis band at $375 \mathrm{~nm}$ and the appearance of a broad low-energy absorption band centered at $\sim 750 \mathrm{~nm}$, while the bands at 270 and $550 \mathrm{~nm}$ remained unchanged. Upon one-electron reduction of 2 at $-1.5 \mathrm{~V}$ vs $\mathrm{Fc} / \mathrm{Fc}^{+}$ (Figure $7 \mathrm{~b}$ ), again a slight decrease in the absorption band at $375 \mathrm{~nm}$ was observed with a negligible change of high-energy band $(270 \mathrm{~nm})$. Furthermore, the intensity of the band at $550 \mathrm{~nm}$ significantly increased. For both redox processes, $\mathbf{2} \rightarrow \mathbf{2}^{\mathrm{Ox}}$ and $\mathbf{2} \rightarrow \mathbf{2}^{\text {Red }}$, full reversibility was observed upon several oxidation / reduction cycles. 
a)

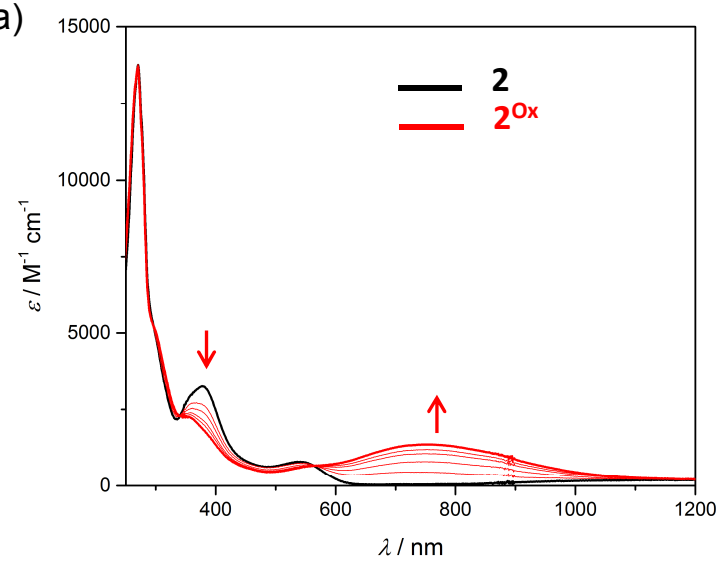

b)

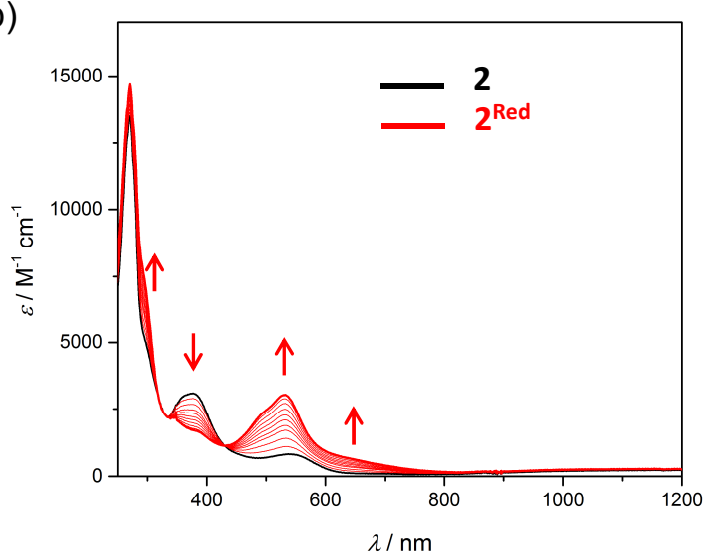

c)

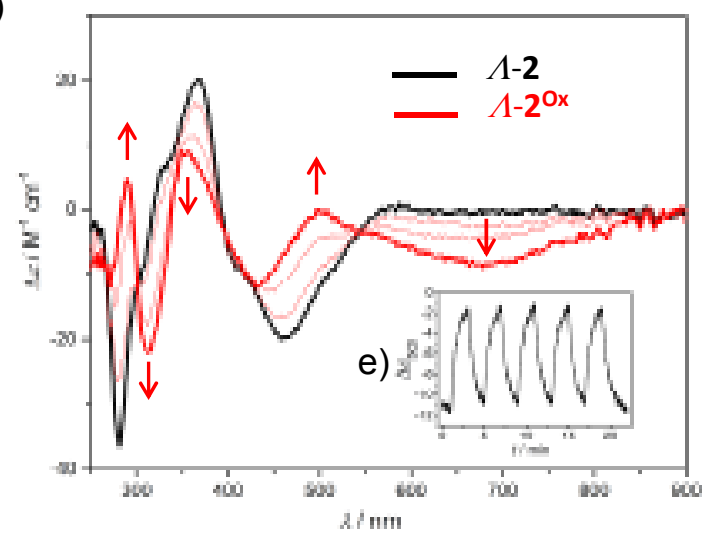

d)

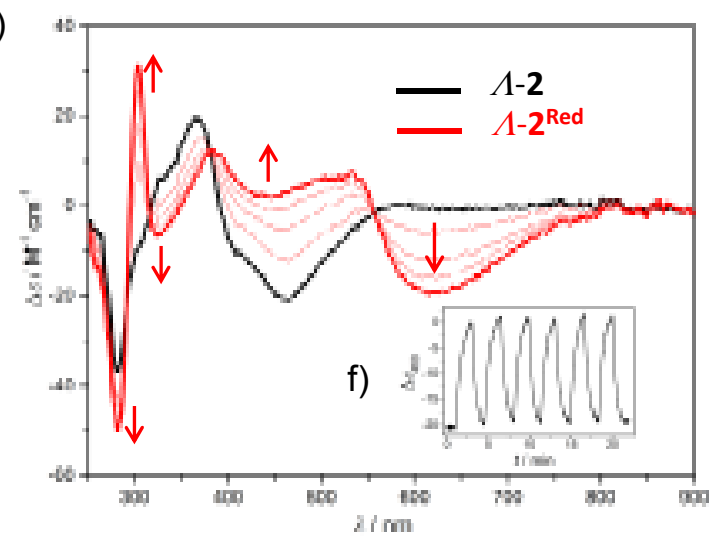

Figure 7. Electrochemical evolution of the experimental UV-vis/NIR spectra of Ru complex 2 upon oxidation (a) and reduction (b). Experimental ECD spectra of enantiopure $1 \mathbf{- 2}$ and of its oxidized $\Lambda-2^{\mathrm{Ox}}$ (c) and reduced $\Lambda-\mathbf{2}^{\text {Red }}$ (d) species. Insets: Reversible $\operatorname{ECD}_{500 \mathrm{~nm}}$ (e) and $\mathrm{ECD}_{460 \mathrm{~nm}}(\mathrm{f})$ switching processes.

Having established that 2 undergoes reversible oxidation and reduction processes, the next step towards electrochemical chiroptical switches was to investigate whether these redox processes impact its chiroptical properties. As seen in Figure 7c, one-electron oxidation $\mathbf{A - 2}$ $\rightarrow \Lambda-2^{\mathrm{Ox}}$ indeed leads to strong modifications of the ECD spectrum in dichloroethane (DCE, $\left.0.2 \mathrm{M} \mathrm{TBAPF}_{6}\right)$. Namely, $\left.i\right)$ the negative ECD-active band at $280 \mathrm{~nm}\left(\Delta \varepsilon=-36 \mathrm{M}^{-1} \mathrm{~cm}^{-1}\right)$ disappeared and a slight positive intensity appeared at $290 \mathrm{~nm}\left(+4 \mathrm{M}^{-1} \mathrm{~cm}^{-1}\right)$, ii) the positivepositive intensity pattern at $330(+6)$ and $367 \mathrm{~nm}\left(+20 \mathrm{M}^{-1} \mathrm{~cm}^{-1}\right)$ was transformed to a blue- 
shifted negative-positive one at $315(-22)$ and $350 \mathrm{~nm}\left(+9 \mathrm{M}^{-1} \mathrm{~cm}^{-1}\right)$, iii) the negative band at $460 \mathrm{~nm}\left(-20 \mathrm{M}^{-1} \mathrm{~cm}^{-1}\right)$ was blue-shifted to 432 with simultaneous decrease in its intensity (12), and $i v$ ) a new broad negative ECD-active band (ranging from 570 to $850 \mathrm{~nm}$ with $\Delta \varepsilon=-9$ $\mathrm{M}^{-1} \mathrm{~cm}^{-1}$ at $680 \mathrm{~nm}$ ) was observed. Exploiting these differences, along with the reversibility of the oxidation process, allows us to obtain an electrochemical chiral switch. Indeed, stepping potentials between 0 and $+1.2 \mathrm{~V}$ of a DCE solution of $\Lambda \mathbf{- 2}$ in an electrochemical cell leads to a reversible modulation of the ECD signals at $500 \mathrm{~nm}$ (Figure 7e) with more than 12 successive oxidation / reduction steps performed.

Similarly, upon one-electron reduction $\Lambda \mathbf{- 2} \rightarrow \Lambda \mathbf{- 2}^{\text {Red }}$, the ECD spectrum (DCE, $0.2 \mathrm{M}$ $\mathrm{TBAPF}_{6}$ ) was strongly modified (Figure 7d). Indeed, $i$ ) the negative ECD-active band at 280 $\mathrm{nm}\left(\Delta \varepsilon=-36 \mathrm{M}^{-1} \mathrm{~cm}^{-1}\right)$ was split into two bands of enhanced negative $\left(282 \mathrm{~nm},-50 \mathrm{M}^{-1} \mathrm{~cm}^{-}\right.$ $\left.{ }^{1}\right)$ and positive intensity $\left(305 \mathrm{~nm},+31 \mathrm{M}^{-1} \mathrm{~cm}^{-1}\right)$, ii) the positive-positive intensity pattern at $330(+6)$ and $367 \mathrm{~nm}\left(+20 \mathrm{M}^{-1} \mathrm{~cm}^{-1}\right)$ was converted to a negative-positive one at $320(-6)$ and $383 \mathrm{~nm}\left(+12 \mathrm{M}^{-1} \mathrm{~cm}^{-1}\right)$, iii $)$ the negative band at $460 \mathrm{~nm}\left(-20 \mathrm{M}^{-1} \mathrm{~cm}^{-1}\right)$ was replaced by a broad positive intensity at $447(+3)$ and $532 \mathrm{~nm}\left(+7 \mathrm{M}^{-1} \mathrm{~cm}^{-1}\right)$, and iv) a new broad negative ECD-active band (ranging from 555 to $810 \mathrm{~nm}$ with $\Delta \varepsilon=-20 \mathrm{M}^{-1} \mathrm{~cm}^{-1}$ at $620 \mathrm{~nm}$ ) appeared. Here again, exploiting the strong differences, along with the reversibility of the reduction process, results in an electrochemical chiral switch. As shown in Figure $7 f$, stepping potentials between -1.5 and $0 \mathrm{~V}$ of a DCE solution of $\Lambda-2$ in an electrochemical cell leads to a reversible (more than 12 steps) modulation of the ECD signals at $460 \mathrm{~nm}$. Remarkably, the redox chiroptical switching of $\mathrm{Ru}(\mathrm{Oacac})_{3}$ complex can be performed both in oxidation and in reduction, thus giving access to three different stable states.

To gain deeper insight into experimentally observed spectral features and their modifications upon one-electron oxidation and reduction of 2, TDDFT UV-vis and ECD calculations were performed for the model $\mathrm{Ru}(\text { Meacac })_{3}$ system in its neutral, oxidized, and 
reduced form. Theory reproduces the general experimental trends for $\mathbf{2}, \mathbf{2}^{\mathbf{O x}}$, and $\mathbf{2}^{\mathrm{Red}}$ in a satisfactory manner (see Figure 8 and Figure S7d in the SI) and therefore enables us to link them to the changes in the electronic structure of the complex occurring upon the redox processes.
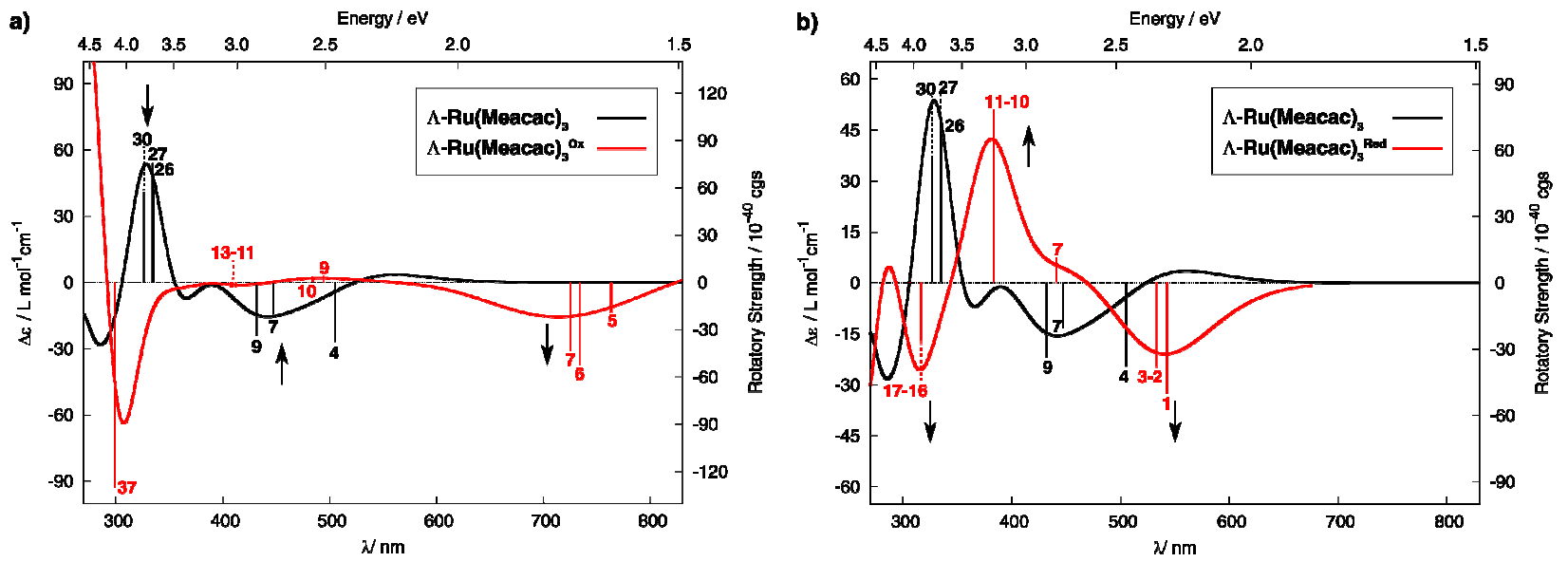

Figure 8. Simulated (TDDFT B3LYP/TZVP, DCE continuum solvent model) ECD spectra of $\Lambda-R u(\text { Meacac })_{3}$ and its oxidized $\Lambda-R u(\text { Meacac })_{3}{ }^{\text {Ox }}(a)$ and reduced form $\Lambda-R u(\text { Meacac })_{3}{ }^{\text {Red }}$ (b). No spectral shift has been applied. Calculated excitation energies and rotatory strengths indicated as 'stick' spectra. Numbered excitations correspond to those analyzed in detail (see SI for a full assignment). Arrows indicate changes in the spectrum due to the redox processes.
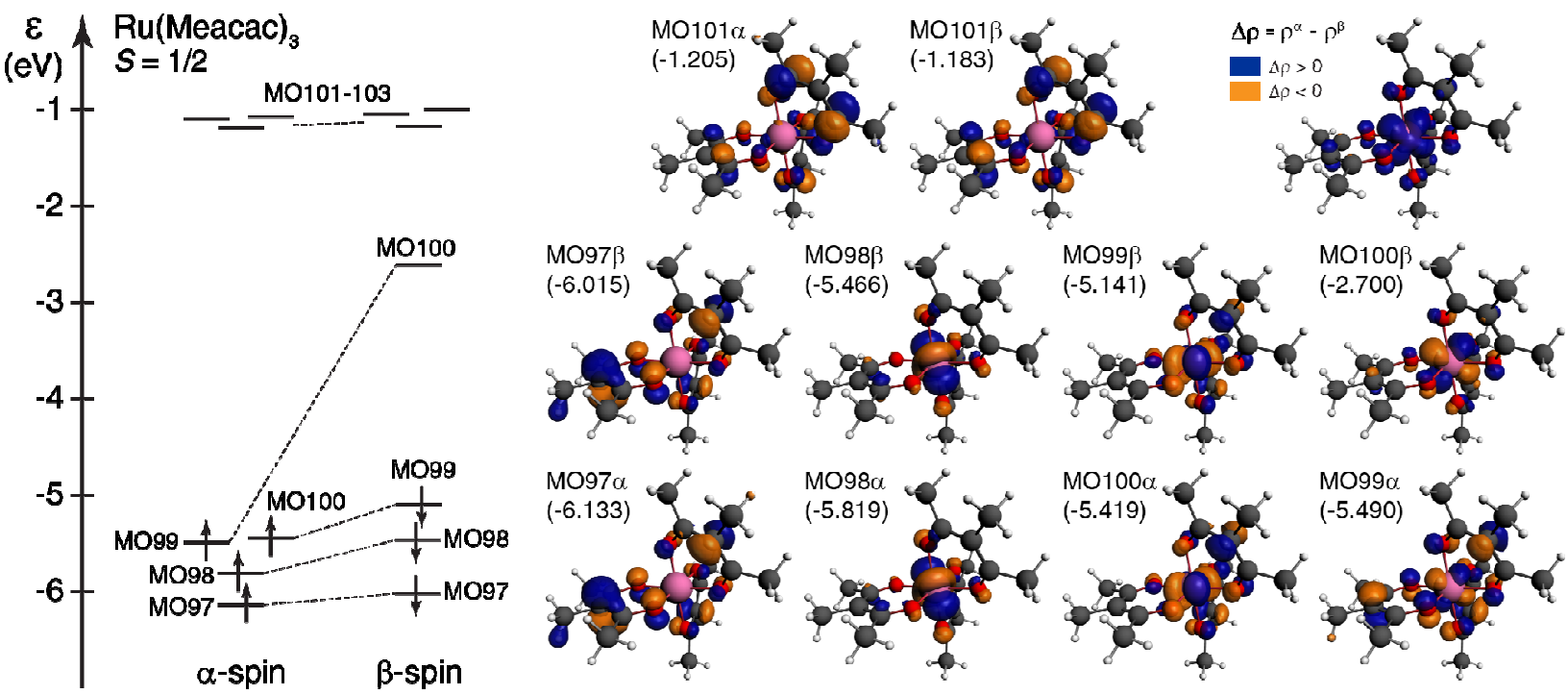
Figure 9. (Left): B3LYP/TZVP MO energy levels (separately for $\alpha$-spin (spin up) and $\beta$-spin (spin down) orbitals) for $\mathrm{Ru}(\text { Meacac })_{3}$. (Right): Isosurfaces $(0.05 \mathrm{au})$ of selected frontier MOs. In parentheses the corresponding orbital energies $\varepsilon$, in $\mathrm{eV}$, are listed. In the right top corner, the isosurface $(0.003 \mathrm{au})$ of the electron spin density $\Delta \rho$ is shown.

The orbital energies and isosurfaces of frontier molecular orbitals (MOs) computed for the neutral $\mathrm{Ru}(\mathrm{III})(\mathrm{Meacac})_{3}$ species are presented in Figure 9 and Figures $\mathrm{S} 7 \mathrm{j}$ in the SI. The system adopts a low-spin $d^{5}$ configuration in line with a strong ligand-field splitting typically observed for $4 d$ complexes. The five highest-energy occupied MOs (98-100 $\alpha$ and 98-99 $\beta$ ) may be classified as metal-ligand out-of-phase combinations of $\mathrm{Ru} d_{\pi}$ (formally $\mathrm{t}_{2 \mathrm{~g}}$ metal $d$ orbitals of local $\pi$ symmetry with respect to the metal-oxygen bonds, i.e. $\left.d_{\mathrm{xy}}, d_{\mathrm{yz}}, d_{\mathrm{xz}}\right)$ with Meacac $\pi$ orbitals, in the following referred to as $d_{\pi}$ due to the dominant metal character. In crystal field theory, these would be the occupied non-bonding metal $4 d$ orbitals; in the DFT calculations there are corresponding in-phase combinations at lower energy, dominantly ligand-centered. The metal-ligand mixing is especially pronounced for the (unpaired) singly occupied MO (SOMO, 99 $\alpha$ ), whose opposite-spin partner orbital (1003) is the lowest-energy unoccupied MO representing an 'electron hole' in the $\beta$-spin density. Note that the numbering is based on the orbital energy, low to high. $99 \alpha$ and $100 \alpha$ are nearly degenerate. The visual comparison of the isosurface plots establishes the pairs of equivalent MOs in the $\alpha$ - and $\beta$-spin MO sets. The term 'SOMO' means that there is no matching occupied orbital in the opposite spin MO set. The metal-ligand orbital mixing reflects dative Ru-Meacac bonding of both Meacac $\rightarrow \mathrm{Ru} \sigma$-and $\pi$-donation (vide infra) and $\mathrm{Ru} \rightarrow$ Meacac $\pi$-backdonation. As expected, the calculated plot of the electron spin density resembles the density of the SOMO $\alpha$-spin $d_{\pi}$ and clearly shows that the unpaired charge density is not only localized on the metal center but to some degree also spread out over the Meacac $\pi$-system. 
See also Figure $\mathrm{S} 7 \mathrm{u}$ in the SI. This confirms a slight donation of the ligand $\beta$-spin $\pi$-density (mostly from oxygen $\pi$-lone-pairs) into the empty $\beta$-spin $\mathrm{Ru} d_{\pi}$.
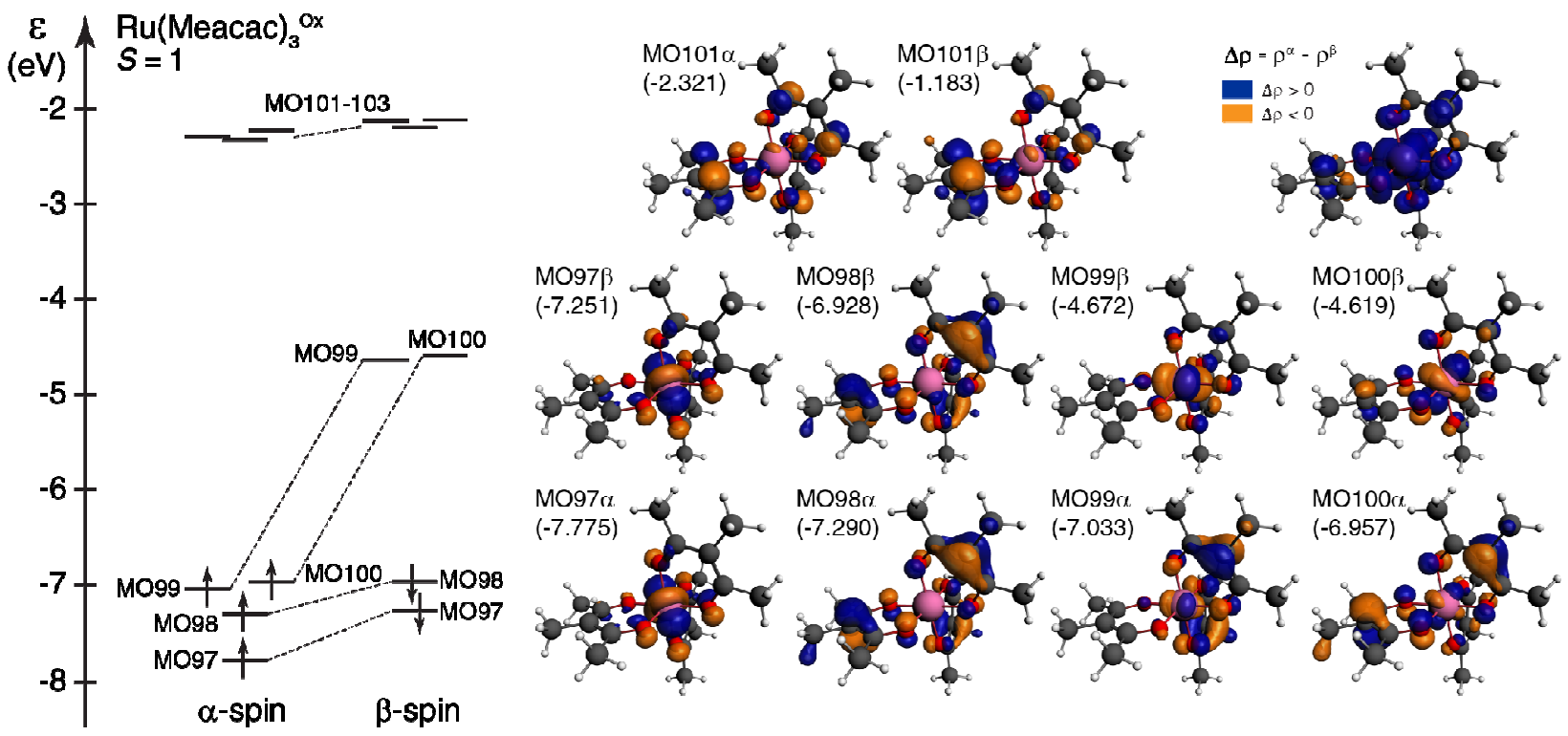

Figure 10. (Left): B3LYP/TZVP MO energy levels (separately for $\alpha$-spin (spin up) and $\beta$ spin (spin down) orbitals) for $\mathrm{Ru}(\mathrm{Meacac})_{3}{ }^{\mathrm{Ox}}$. (Right): Isosurfaces $(0.05 \mathrm{au})$ of selected frontier MOs. In parentheses the corresponding orbital energies $\varepsilon$, in $\mathrm{eV}$, are listed. In the right top corner, the isosurface $(0.003 \mathrm{au})$ of the electron spin density $\Delta \rho$ is shown.

Oxidation of the neutral $\mathrm{Ru}(\mathrm{III})(\text { Meacac })_{3}$ yields cationic $\mathrm{Ru}(\mathrm{IV})(\text { Meacac })_{3}{ }^{\text {Ox }}$ with a spintriplet $d^{4}$ electronic configuration and two unoccupied $\beta$-spin $\mathrm{Ru} d_{\pi}$ orbitals $(99-100 \beta)$. Accordingly, there are two $\alpha$-spin SOMOs (99-100 $\alpha$, see Figure 10). Although the orbital picture is generally the same for $\mathrm{Ru}(\text { Meacac) })_{3}$ and $\mathrm{Ru}\left(\right.$ Meacac) ${ }_{3}{ }^{\mathrm{Ox}}$ (see also Figures $\mathrm{S} 7 \mathrm{k}$ in the SI), a high energetic stabilization of metal-centered orbitals (especially pronounced in the case of $\beta$-spin 'electron hole' $d_{\pi}$ MOs) and a decrease in the metal character of occupied $d_{\pi^{-}}$ based metal-ligand antibonding combinations in $\mathrm{Ru}(\text { Meacac })_{3}{ }^{\text {Ox }}$ can be noted. These changes can be considered as consequences of the metal-centered oxidation that leads to a decrease in 
the electron repulsion within the $d$ shell and to an increase in the $\beta$-spin $\pi$-acceptor ability of the $\mathrm{Ru}$ ion. The latter is nicely illustrated by the plot of electron spin density. The $\beta$-spin $\pi$ donation from Meacac to the empty $\beta$-spin $\operatorname{Ru}(\mathrm{IV}) d_{\pi}$, enhanced by the oxidation, results in the more pronounced excess of $\alpha$-spin $\pi$-density in the ligand (see also Figure S7u in the SI). On the contrary, reduction of the neutral Ru(III)(Meacac) $)_{3}$ to the anionic $\mathrm{Ru}(\mathrm{II})(\mathrm{Meacac})_{3}{ }^{\mathrm{Red}}$ gives a closed-shell $d^{6}$ configuration (see Figures $\mathrm{S} 7 \mathrm{v}$ and $\mathrm{S} 71$ in the $\mathrm{SI}$ ), a pronounced destabilization of the occupied $d_{\pi}$-based MOs, and an increase in their non-bonding character due to the elimination of the Meacac $\rightarrow \operatorname{Ru}(\mathrm{II}) \pi$-donation channel.

The analysis of selected dominant excitations of $\Lambda-\mathrm{Ru}(\text { Meacac })_{3}, \Lambda-\mathrm{Ru}(\mathrm{Meacac})_{3}{ }^{\mathrm{Ox}}$, and $\Lambda-\mathrm{Ru}(\mathrm{Meacac})_{3}{ }^{\mathrm{Red}}$ in terms of individual MO pairs (see the SI for the full set of data) shows that the aforementioned differences in the electronic structure of these species are reflected in the corresponding electronic spectra. For example, the new broad negative ECD band appearing around $700 \mathrm{~nm}$ upon oxidation of the $\mathrm{Ru}(\mathrm{III})$ complex is assigned as predominantly $\pi-\pi^{*}$ ligand-to-metal charge-transfer (LM CT) from the $\beta$-occupied metalligand bonding MOs to the $d_{\pi} \beta$-'electron holes' (excitations nos. 5-7, Figure 8a). An excitation with an analogous assignment can also be found for $\mathrm{Ru}(\text { Meacac })_{3}$ but it is strongly blue-shifted (no. 4, $505 \mathrm{~nm}$ ) compared to $\mathrm{Ru}\left(\right.$ Meacac) ${ }_{3}{ }^{\mathrm{Ox}}$ in line with the destabilization of the unoccupied $\beta$-spin $d_{\pi}$. The decrease in the intensity of the negative ECD band at ca. 450 $\mathrm{nm}$ and modifications of the positive band around $350 \mathrm{~nm}$ observed experimentally upon oxidation of 2 can be traced back mainly to changes in the character of the frontier MOs rather than new transitions. As far as the one-electron reduction of $\mathbf{2}$ is concerned, the differences in the spectra of $\mathbf{2}$ vs. $2^{\text {Red }}$ can be linked, with the help of the calculations, to 1) absence of contributions involving $\beta$-'electron hole' $d_{\pi}$ orbitals, 2 ) the $\mathrm{Ru} d_{\pi}$ orbitals becoming non-bonding upon reduction, and 3) destabilization of the $\mathrm{Ru} 4 d$ orbitals due to the 
increased electron repulsion in the $d$ shell. In combination, these changes enable low-energy ML CT transitions (e.g. excitations nos. 1-3, Figure 8b).

The one-electron oxidation of 4 into $4^{\mathrm{Ox}}\left(\mathrm{Cr}^{\mathrm{III}} / \mathrm{Cr}^{\mathrm{IV}}\right)$ was also followed by UV-vis/NIR spectroscopy in an OTTLE cell (DCE, $0.2 \mathrm{M} \mathrm{TBAPF}_{6}$, at $1.5 \mathrm{~V}$ vs $\mathrm{Fc} / \mathrm{Fc}^{+}$). The measurements showed a slight decrease in intensity of the high-energy bands at 271 and 356 $\mathrm{nm}$ and the appearance of three new broad absorption bands centered at around 475, 805, and $1100 \mathrm{~nm}$ (see Figure 11a). As for Ru complex 2, full reversibility was observed upon several oxidation / reduction cycles. The $\Lambda-4 \rightarrow \Lambda-4^{0 x}$ redox process was then examined by ECD spectroscopy. As shown in Figure $11 \mathrm{~b}$, the ECD spectra of $\Lambda-\mathbf{4}$ and $\Lambda-4^{\mathbf{O x}}$ in DCE revealed generally the same spectral envelopes. However, upon oxidation all ECD-active bands underwent a strong decrease in intensity, and a new broad negative ECD-active band centered at $\sim 850 \mathrm{~nm}\left(\Delta \varepsilon=-10 \mathrm{M}^{-1} \mathrm{~cm}^{-1}\right)$ appeared. Stepping potentials between 0 and $+1.5 \mathrm{~V}$ of a DCE solution of $\Lambda-4$ in an OTTLE cell leads to a reversible modulation of the ECD signals at $840 \mathrm{~nm}$ (Figure 11c) with more than 12 successive oxidation / reduction steps performed which confirms electrochemical chiroptical switching of 4 .

a)

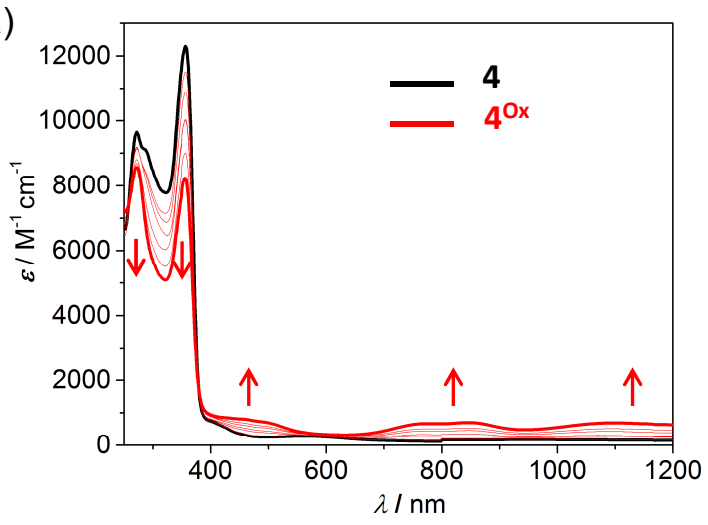

b)

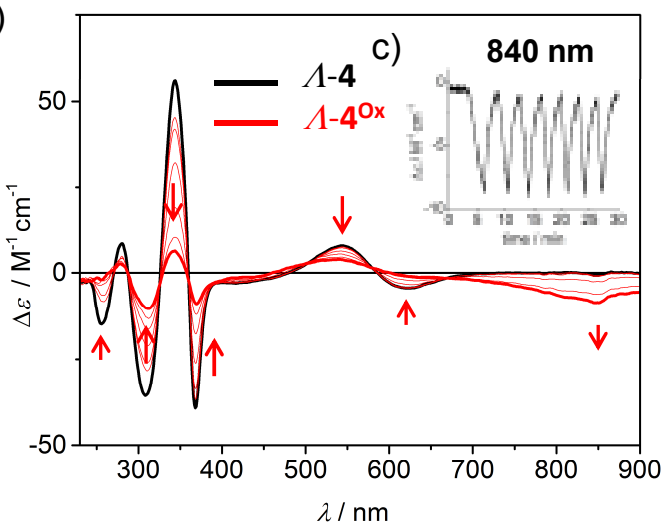


Figure 11. (a) Electrochemical evolution of the experimental UV-vis/NIR spectra of $\mathrm{Cr}$ complex 4 upon oxidation. (b) Experimental ECD spectra of enantiopure $\mathbf{A - 4}$ and of its oxidized $1-4^{\text {Ox }}$ species. Inset (c): Reversible $\mathrm{ECD}_{840 \mathrm{~nm}}$ switching process.

In the calculations, the model $\mathrm{Cr}(\text { Meacac })_{3}$ complex adopts a spin-quartet $d^{3}$ electronic configuration with three unpaired $\alpha$-spin SOMOs that represent metal-ligand out-of-phase combinations of predominantly $\operatorname{Cr} d_{\pi}$ with Meacac $\pi$ orbitals. The three corresponding empty $\beta$-spin MOs display metal-ligand $\pi$-character. Accordingly, the calculated electron spin density resembles a sum of the densities of the three SOMOs, resulting in an isosurface with a cubic shape (see Figures S7w1 and S7u in the SI). With three $\beta$-spin 'electron holes' one might expect pronounced $\beta$-spin Meacac $\rightarrow$ metal $\pi$-donation. Interestingly, there is no indication that such a mechanism takes place to any significant degree in $\mathrm{Cr}(\mathrm{Meacac})_{3}$. An intuitive explanation is that a ligand-to-metal $\beta$-spin density donation would disrupt a halffilled $d_{\pi}$ shell configuration at the metal center. This is consistent with the small metal $d$ contributions in the oxygen $\pi$-lone-pairs calculated previously for the parent $\operatorname{Cr}(\mathrm{acac})_{3}$ complex. ${ }^{63}$ Oxidation of the neutral $\mathrm{Cr}(\mathrm{III})$ system leads to a cationic $\mathrm{Cr}(\mathrm{Meacac})_{3}{ }^{\mathrm{Ox}}$ species with a spin-triplet $d^{2}$ configuration with one of the metal $d_{\pi}$ orbitals in the $\alpha$-spin set now being formally unoccupied (see Figures S7w2 and S7u in the SI). However, in the cationic complex a pronounced $\alpha$-spin Meacac $\rightarrow$ metal $\pi$-donation partially restores the half-filled $d_{\pi}$ shell at Cr. In turn, this donation leaves a sizable excess of $\beta$-spin density at the ligands, as seen in the plot of the corresponding electron spin density. The corresponding unoccupied $\alpha-$ spin MO representing the 'electron hole' has large contributions from the ligands (Figure $\mathrm{S} 7 w 2)$. As for $\mathrm{Ru}(\mathrm{Meacac})_{3}{ }^{\mathrm{Ox}}$, an energetic stabilization of unoccupied $\alpha$ - and $\beta$-spin $\mathrm{Cr} d_{\pi}$ orbitals can be noted in the oxidized $\mathrm{Cr}$ complex. 
The simulated UV-vis and ECD spectra of $\Lambda-\mathrm{Cr}(\text { Meacac) })_{3}$ and $\Lambda-\mathrm{Cr}(\mathrm{Meacac})_{3}{ }^{\text {Ox }}$ (Figure 12 and Figure S7d in the SI) show overall similar features as the corresponding experimental ones for 4 and $4^{\mathbf{O x}}$. The ECD spectrum for $\mathrm{Cr}(\mathrm{acac})_{3}$ has been assigned in ref. 78 based on TDDFT calculations, and therefore we forego a detailed discussion. The new broad negative ECD band observed around $850 \mathrm{~nm}$ upon oxidation of the $\mathrm{Cr}$ (III) system involves transitions from the $\alpha$-occupied metal-ligand-centered MOs to the $d_{\pi}$ ' $\alpha$-electron hole' created upon oxidation (excitations nos. 4-5, Figure 12). The differences in the spectra of 4 vs. $4^{\text {Ox }}$ observed in the remaining spectral regions can be primarily traced back to large changes in the character of the frontier MOs due to the one-electron oxidation process.

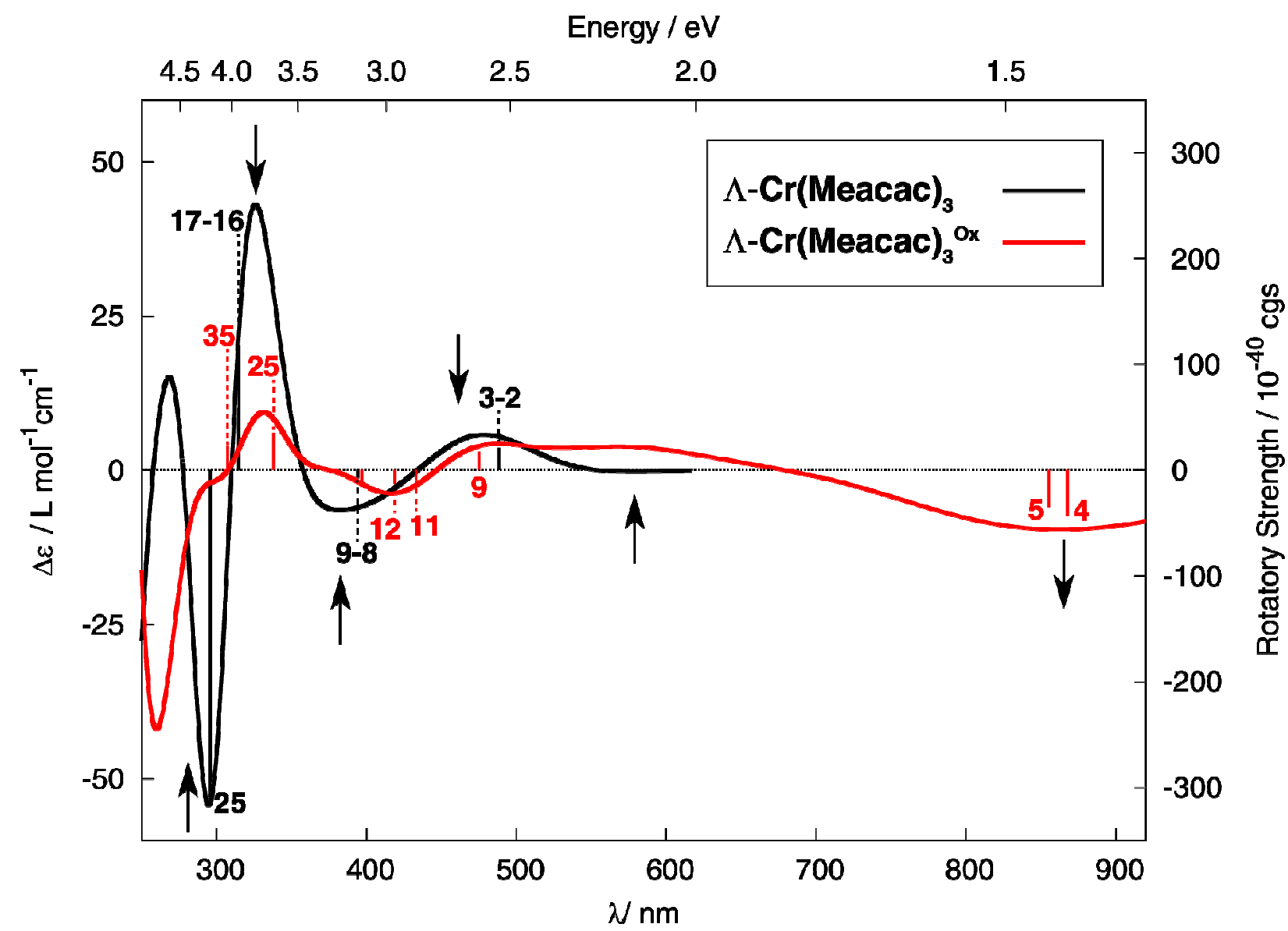

Figure 12. Simulated (TDDFT B3LYP/TZVP, DCE continuum solvent model) ECD spectra of $\Lambda$-Cr(Meacac $)_{3}$ and its oxidized form $\Lambda$-Cr(Meacac $)_{3}{ }^{\text {ox }}$. No spectral shift has been applied. Calculated excitation energies and rotatory strengths indicated as 'stick' spectra. Numbered 
excitations correspond to those analyzed in detail (see SI for a full assignment). Arrows indicate changes in the spectrum due to the redox process.

Finally, the electrochemical switching activity of the Co complex 5 was examined. Unfortunately, in this case no efficient and reversible processes were observed due to the low stability of the neutral complex which seems to decompose upon oxidation by ligand decomplexation. The experimental findings may be rationalized by the calculated electronic structure of the oxidized $\mathrm{Co}(\mathrm{IV})(\mathrm{Meacac})_{3}$ species. The neutral $\mathrm{Co}(\mathrm{III})$ complex has a lowspin closed-shell $d^{6}$ configuration (see Figure S7x1 in the SI). One-electron oxidation leads to a doublet species, but with a ligand-centered spin density. This means that the oxidation does not occur at the metal center, or, if the oxidation initially creates a Co(IV) complex with a $\beta$ spin 'electron hole' at the metal, the acac ligand immediately donates $\beta$-spin density to the metal, restoring a filled set of $\mathrm{d}_{\pi}$ orbitals at Co and leaving an excess of $\alpha$-spin $\pi$-density in the ligand system (Figures S7x2 and S7u, SI). The assignment of calculated ECD spectrum of $\mathrm{Co}(\text { Meacac })_{3}$ generally follows the one reported for $\mathrm{Co}(\mathrm{acac})_{3}{ }^{77-78}$ and is therefore not discussed here in detail. The interested reader is referred to the SI.

\section{Conclusions}

Five new chiral tris( $\beta$-diketonato) complexes of ruthenium(III), chromium(III), and cobalt(III) have been synthesized and characterized by a varied set of techniques. They have been optically resolved into pure enantiomers using preparative supercritical fluid chromatography. ECD measurements have allowed the absolute configurations assignment. Spectroelectrochemical UV-vis and ECD studies have demonstrated that $\mathrm{Ru}$ and $\mathrm{Cr}$ complexes $\Lambda$-2 and $\Lambda$-4 reveal efficient redox-triggered chiroptical switching activity. The 
first-principles calculations have reproduced experimentally observed spectral features of 1-5 and their modifications upon redox processes in a satisfactory manner. The analysis of the results of the calculations shows that the changes in the electronic state of a given complex explain the observed spectral changes upon oxidation and reduction, rather than structural changes.

\section{Acknowledgements}

This work was supported by the COMOCHOL project within the "Emergence 2013" program from 'Projects Initiatives d'excellence idex UNITI' under convention UT: 2014-590 and by the CNRS (Chirafun network). The enantiopurification scale-up was carried out on Prep80Q which is an equipment of the Institut de Chimie de Toulouse (ICT). The chiral analysis was performed on $\mathrm{UPC}^{2}$ (Waters) equipment which is a part of the Integrated Screening Platform of Toulouse (PICT, IBISA). We acknowledge Dr. Michel Mitov for fruitful discussions on liquid crystal physics. M.S.-H. is grateful for financial support from the Ministry of Science and Higher Education in Poland ('Outstanding Young Scientist' scholarship and young researchers' T-subsidy). J.A. acknowledges the National Science Foundation (CHE 1560881 and 1265833) for financial support and the Center for Computational Research (CCR) at the University at Buffalo for computational resources.

\section{Supporting Information Available}

X-ray crystallographic data for complexes 1 and 5 in CIF format. S1. Supercritical fluid chromatography (SFC) files; S2. NMR spectra of the ligands; S3. NMR spectra of the complexes; S4. Infrared spectra of the complexes; S5. Crystallographic data; S6. Cyclic Voltammetry; S7. Additional calculated data . 


\section{References}

(1) Amouri, H., Gruselle, M. Chirality in Transition Metal Chemistry, Wiley-VCH, 2008.

(2) Sierra, T. Chirality at the Nanoscale, Nanoparticles, Surfaces, Materials and more; Amabilino, D. (eds.), Wiley-VCH, 2009. 115-189.

(3) Drake, A. F., Gottarelli, G., Spada, G. P. The twisting power of some chiral tris(pentane-2,4-dionato)metal(III) complexes in nematic liquid-crystals. Chem. Phys. Lett. 1984, $110,630-633$.

(4) Hoshino, N., Matsuoka, Y., Okamoto, K., Yamagishi, A. Delta- Ru(acac)(2)L (L = a mesogenic derivative of bpy) as a novel chiral dopant for nematic liquid crystals with large helical twisting power. J. Amer. Chem. Soc. 2003, 125, 1718-1719.

(5) Yoshida, J., Watanabe, G., Kakizawa, K., Kawabata, Y., Yuge, H. Tris(betadiketonato) $\mathrm{Ru}$ (III) Complexes as Chiral Dopants for Nematic Liquid Crystals: the Effect of the Molecular Structure on the Helical Twisting Power. Inorg. Chem. 2013, 52, 11042-11050.

(6) Anzai, N., Kurihara, H., Sone, M., Furukawa, H., Watanabe, T., Horie, K., Kumar, S. Light-induced formation of curved needle texture by circularly polarized light irradiation on a discotic liquid crystal containing a racemic chromium complex. Liquid Crystals 2006, 33, 671-679.

(7) Anzai, N., Machida, S., Horie, K. Chirooptical control of liquid crystalline textures containing chromium complex by irradiation of circular polarized light. Chem. Lett. 2001, 888-889.

(8) Anzai, N., Machida, S., Horie, K. Light-induced control of textures and cholesteric pitch in liquid crystals containing chromium complexes, by means of circular and linear polarized light. Liquid Crystals 2003, 30, 359-366.

(9) Sato, H., Yamagishi, A. Application of Delta- and Lambda-Isomerism of Octahedral Metal Complexes for Inducing Chiral Nematic Phases. Int. J. Mol. Sci. 2009, 10, 4559-4574.

(10) Sato, H., Yamagishi, A. Application of the Delta Lambda isomerism of octahedral metal complexes as a chiral source in photochemistry. J. Photochem. Photobiol. C: Photochem. Rev. 2007, 8, 67-84.

(11) Sato, H., Sato, F., Yamagishi, A. Rewritable optical memory in liquid crystals containing photo-epimerizing Cr(III) complexes. Chem. Comm. 2013, 49, 4773-4775.

(12) Mitov, M. Cholesteric Liquid Crystals with a Broad Light Reflection Band. Adv. Mater. 2012, 24, 6260-6276.

(13) Das, A., Ghosh, P., Plebst, S., Schwederski, B., Mobin, S. M., Kaim, W., Lahiri, G. $\mathrm{K}$. Ancillary Ligand Control of Electronic Structure in o-Benzoquinonediimine-Ruthenium Complex Redox Series: Structures, Electron Paramagnetic Resonance (EPR), and UltravioletVisible-Near-Infrared (UV-vis-NIR) Spectroelectrochemistry. Inorg. Chem. 2015, 54, 33763386.

(14) Das, D., Sarkar, B., Kumbhakar, D., Mondal, T. K., Mobin, S. M., Fiedler, J., Urbanos, F. A., Jimenez-Aparicio, R., Kaim, W., Lahiri, G. K. Bis(acetylacetonato)ruthenium Complexes of Noninnocent 1,2-Dioxolene Ligands: Qualitatively Different Bonding in Relation to Monoimino and Diimino Analogues. Chem. Eur. J. 2011, 17, 11030-11040.

(15) Grupp, A., Bubrin, M., Ehret, F., Zeng, Q., Hartl, F., Kvapilova, H., Zalis, S., Kaim, W. Ru-II(alpha-diimine) or Ru-III(alpha-diimine(center dot-))? Structural, Spectroscopic, and Theoretical Evidence for the Stabilization of a Prominent Metal-to-Ligand Charge-Transfer Excited-State Configuration in the Ground State. Eur. J. Inorg. Chem. 2014, 2014, 110-119.

(16) Mandal, A., Grupp, A., Schwederski, B., Kaim, W., Lahiri, G. K. Varying Electronic Structures of Diosmium Complexes from Noninnocently Behaving Anthraquinone-Derived Bis-chelate Ligands. Inorg. Chem. 2015, 54, 7936-7944. 
(17) Mandal, A., Kundu, T., Ehret, F., Bubrin, M., Mobin, S. M., Kaim, W., Lahiri, G. K. Varying electronic structural forms of ruthenium complexes of non-innocent 9,10phenanthrenequinonoid ligands. Dalton Trans. 2014, 43, 2473-2487.

(18) McKinnon, S. D. J., Patrick, B. O., Lever, A. B. P., Hicks, R. G. Electronic Structure Investigations of Neutral and Charged Ruthenium Bis(beta-diketonate) Complexes of RedoxActive Verdazyl Radicals. J. Amer. Chem. Soc. 2011, 133, 13587-13603.

(19) Mondal, P., Agarwala, H., Jana, R. D., Plebst, S., Grupp, A., Ehret, F., Mobin, S. M., Kaim, W., Lahiri, G. K. Sensitivity of a Strained C-C Single Bond to Charge Transfer: Redox Activity in Mononuclear and Dinuclear Ruthenium Complexes of Bis(arylimino)acenaphthene (BIAN) Ligands. Inorg. Chem. 2014, 53, 7389-7403.

(20) Mondal, P., Das, A., Lahiri, G. K. The Electron-Rich $\{\mathrm{Ru}(\mathrm{acac})(2)\}$ Directed Varying Configuration of the Deprotonated Indigo and Evidence for Its Bidirectional Noninnocence. Inorg. Chem. 2016, 55, 1208-1218.

(21) Fabre, M., Jaud, J., Hliwa, M., Launay, J. P., Bonvoisin, J. On the role of the bridging dicyanamidobenzene ligand in a new binuclear ruthenium complex: $\{\operatorname{Ru}(\operatorname{tpy})(\mathrm{thd})\}(2)(\mathrm{mu}-$ dicyd) PF6 with tpy=2,2 ': 6 ',2 "-terpyridine and thd=2,2,6,6-tetramethyl-3,5-heptanedione. Inorg. Chem. 2006, 45, 9332-9345.

(22) Anger, E., Srebro, M., Vanthuyne, N., Toupet, L., Rigaut, S., Roussel, C., Autschbach, J., Crassous, J., Reau, R. Ruthenium-Vinylhelicenes: Remote Metal-Based Enhancement and Redox Switching of the Chiroptical Properties of a Helicene Core. J. Amer. Chem. Soc. 2012, 134, 15628-15631.

(23) Srebro, M., Anger, E., Mooreii, B., Vanthuyne, N., Roussel, C., Reau, R., Autschbach, J., Crassous, J. Ruthenium-Grafted Vinylhelicenes: Chiroptical Properties and Redox Switching. Chem. Eur. J. 2015, 21, 17100-17115.

(24) Kashiwara, S., Takahashi, M., Nakata, M., Taniguchi, M., Yamagishi, A. Resolution of optically active tris- and bis(diketonato) metal(III) complexes and their monolayer properties at an air-water interface. J. Mater. Chem. 1998, 8, 2253-2257.

(25) Okamoto, K., Matsuoka, Y., Wakabayashi, N., Yamagishi, A., Hoshino, N. The effect of Delta Lambda chirality on molecular organization in two-dimensional films of a $\mathrm{Ru}$ (II) complex with a mesogenic ligand. Chem. Comm. 2002, 282-283.

(26) Matsuoka, Y., Sato, H., Yamagishi, A., Okamoto, K., Hoshino, N. Delta LambdaIsomerism of mixed 1,3-diketonate complexes of $\mathrm{Ru}(\mathrm{III})$ - A designed new source of chirality in nematic liquid crystals. Chem. Mater. 2005, 17, 4910-4917.

(27) Munery, S., Ratel-Ramond, N., Benjalal, Y., Vernisse, L., Guillermet, O., Bouju, X., Coratger, R., Bonvoisin, J. Synthesis and Characterization of a Series of Ruthenium Tris(beta-diketonato) Complexes by an UHV-STM Investigation and Numerical Calculations. Eur. J. Inorg. Chem. 2011, 2698-2705.

(28) Vernisse, L., Munery, S., Ratel-Ramond, N., Benjalal, Y., Guillermet, O., Bouju, X., Coratger, R., Bonvoisin, J. UHV-STM Investigations and Numerical Calculations of a Ruthenium beta-Diketonato Complex with Protected Ethynyl Ligand: $\mathrm{Ru}(\mathrm{dbm})(2)(\mathrm{acac}-$ TIPSA). J. Phys. Chem. C 2012, 116, 13715-13721.

(29) Bonvoisin, J., Ciofini, I. Spectral signature of a Ru(II, III, IV) complex: a combined experimental and theoretical investigation. Dalton Trans. 2013, 42, 7943-7951.

(30) Mitsuoka, T., Sato, H., Yoshida, J., Yamagishi, A., Einaga, Y. Photomodulation of a chiral nematic liquid crystal by the use of a photoresponsive ruthenium(III) complex. Chem. Mater. 2006, 18, 3442-3447.

(31) Yoshida, J., Sato, H., Hoshino, N., Yamagishi, A. Induction and structural control of chiral nematic phases by the use of photoresponsive tris(beta-diketonato) $\mathrm{Co}$ (III) and $\mathrm{Ru}(\mathrm{III})$ complexes. J. Phys. Chem. B 2008, 112, 9677-9683. 
(32) Yoshida, J., Sato, H., Yamagishi, A., Hoshino, N. On the parity in helical twisting power of Ru(III) 1,3-diketonates of C-2 symmetry in nematic liquid crystals. J. Amer. Chem. Soc. 2005, 127, 8453-8456.

(33) Sato, H., Taniguchi, T., Nakahashi, A., Monde, K., Yamagishi, A. Effects of central metal ions on vibrational circular dichroism spectra of Tris-(beta-diketonato)metal(III) complexes. Inorg. Chem. 2007, 46, 6755-6766.

(34) Wang, Y., Liu, M., Cao, R., Zhang, W., Yin, M., Xiao, X., Liu, Q., Huang, N. A Soluble Bis-Chelated Gold(I) Diphosphine Compound with Strong Anticancer Activity and Low Toxicity. J. Med. Chem. 2013, 56, 1455-1466.

(35) Speybrouck, D., Lipka, E. Preparative supercritical fluid chromatography: A powerful tool for chiral separations. Journal of Chromatography A 2016, 1467, 33-55.

(36) Bruker APEX2 (Version 2012.10-0), SAINT (version 8.27B), SADABS (version 2012/1): BrukerAXS Inc., Madison, Wisconsin, USA, 2012.

(37) SIR2011: a new package for crystal structure determination and refinement Burla, $\mathrm{M}$. C., Caliandro, R., Camalli, M., Carrozzini, B., Cascarano, G. L., Giacovazzo, C., Mallamo, M., Mazzone, A., Polidori, G., Spagna, R., J. of Appl. Cryst., 2012 45, 357-361.

(38) WINGX: A MS-Windows System of Programs for Solving, Refining and Analysing Single Crystal X-ray Diffraction Data for Small Molecules Farrugia, L. J., University of Glasgow, Glasgow, 2005.

(39) SHELXS/L-97: Programs for Crystal Structure Determination. Sheldrick, G. M., University of Göttingen, Germany, 1997.

(40) Carlucci, L., Ciani, G., Maggini, S., Proserpio, D. M., Visconti, M. Heterometallic Modular Metal-Organic 3D Frameworks Assembled via New Tris-beta-Diketonate Metalloligands: Nanoporous Materials for Anion Exchange and Scaffolding of Selected Anionic Guests. Chem. Eur. J. 2010, 16, 12328-12341.

(41) TURBOMOLE v6.6, a development of University of Karlsruhe and Forshungszentrum Karlsruhe GmbH, 1989-2007, TURBOMOLE GmbH, since 2007; available from http://www.turbomole.com 2014

(42) Ahlrichs, R., Bar, M., Haser, M., Horn, H., Kolmel, C. Electronic structure calculations on workstation computers - The program system Turbomole. Chem. Phys. Lett. 1989, 162, 165-169.

(43) Furche, F., Ahlrichs, R., Hattig, C., Klopper, W., Sierka, M., Weigend, F. Turbomole. WIREs Comp. Mol. Sci. 2014, 4, 91-100.

(44) Lee, C. T., Yang, W. T., Parr, R. G. Development of the Colle-Salvetti correlationenergy formula into a functional of the electron-density. Phys. Rev. B 1988, 37, 785-789.

(45) Becke, A. D. Density-functional thermochemistry .3. the role of exact exchange. $J$. Chem. Phys. 1993, 98, 5648-5652.

(46) Stephens, P. J., Devlin, F. J., Chabalowski, C. F., Frisch, M. J. Ab-initio calculation of vibrational absorption and circular-dichroism spectra using density-functional force-fields. $J$. Phys. Chem. 1994, 98, 11623-11627.

(47) Becke, A. D. Density-functional exchange-energy approximation with correct asymptotic behavior. Phys. Rev. A 1988, 38, 3098-3100.

(48) Perdew, J. P. Density-functional approximation for the correlation-energy of the inhomogeneous electron-gas. Phys. Rev. B 1986, 33, 8822-8824.

(49) Perdew, J. P. Correction. Phys. Rev. B 1986, 34, 7406.

(50) Adamo, C., Barone, V. Toward reliable density functional methods without adjustable parameters: The PBE0 model. J. Chem. Phys. 1999, 110, 6158-6170.

(51) Weigend, F., Ahlrichs, R. Balanced basis sets of split valence, triple zeta valence and quadruple zeta valence quality for $\mathrm{H}$ to Rn: Design and assessment of accuracy. Phys. Chem. Chem. Phys. 2005, 7, 3297-3305. 
(52) Andrae, D., Haussermann, U., Dolg, M., Stoll, H., Preuss, H. Energy-adjusted abinitio pseudopotentials for the 2nd and 3rd row transition-elements. Theoret. Chim. Acta 1990, 77, 123-141.

(53) Klamt, A., Schuurmann, G. COSMO - A new approach to dielectric screening in solvents with explicit expressions for the screening energy and its gradient. J. Chem. Soc., Perkin Trans. 1993, 799-805.

(54) Klamt, A. Calculation of UV/Vis spectra in solution. J. Phys. Chem. 1996, 100, 33493353.

(55) Scalmani, G., Frisch, M. J., Mennucci, B., Tomasi, J., Cammi, R., Barone, V. Geometries and properties of excited states in the gas phase and in solution: Theory and application of a time-dependent density functional theory polarizable continuum model. $J$. Chem. Phys. 2006, 124.

(56) Autschbach, J., Ziegler, T., van Gisbergen, S. J. A., Baerends, E. J. Chiroptical properties from time-dependent density functional theory. I. Circular dichroism spectra of organic molecules. J. Chem. Phys. 2002, 116, 6930-6940.

(57) Cativiela, C., Serrano, J. L., Zurbano, M. M. Synthesis of 3-substituted pentane-2,4diones - Valuable intermediates for liquid-crystals. J. Org. Chem. 1995, 60, 3074-3083.

(58) Endo, A., Kajitani, M., Mukaida, M., Shimizu, K., Sato, G. P. A new synthetic method for ruthenium complexes of beta-diketones from ruthenium blue solution and their properties. Inorg. Chim. Acta 1988, 150, 25-34.

(59) Hoshino, Y., Eto, M., Fujino, T., Yukawa, Y., Ohta, T., Endo, A., Shimizu, K., Sato, G. P. Synthesis and characterization of mixed-ligand ruthenium(III) complexes with oxalate and acetylacetonate ions. Inorg. Chim. Acta 2004, 357, 600-604.

(60) Munery, S., Jaud, J., Bonvoisin, J. Synthesis and characterization of bis(bipyridine)ruthenium(II) complexes with bromo or protected ethynyl beta-diketonato ligands. Inorg. Chem. Comm. 2008, 11, 975-977.

(61) Rastrelli, F., Bagno, A. Predicting the NMR Spectra of Paramagnetic Molecules by DFT: Application to Organic Free Radicals and Transition-Metal Complexes. Chem. Eur. J. 2009, 15, 7990-8004.

(62) Rastrelli, F., Bagno, A. Predicting the H-1 and C-13 NMR spectra of paramagnetic $\mathrm{Ru}(\mathrm{III})$ complexes by DFT. Magn. Res. Chem. 2010, 48, S132-S141.

(63) Pritchard, B., Autschbach, J. Theoretical Investigation of Paramagnetic NMR Shifts in Transition Metal Acetylacetonato Complexes: Analysis of Signs, Magnitudes, and the Role of the Covalency of Ligand-Metal Bonding. Inorg. Chem. 2012, 51, 8340-8351.

(64) Connelly, N. G., Geiger, W. E. Chemical redox agents for organometallic chemistry. Chem. Rev. 1996, 96, 877-910.

(65) Endo, A., Hoshino, Y., Hirakata, K., Takeuchi, Y., Shimizu, K., Furushima, Y., Ikeuchi, H., Sato, G. P. Electrochemistry of tris(beta-diketonato)ruthenium(III) complexes at platinum electrodes in nonaqueous solutions and substituent effects on their reversible halfwave potentials. Bull. Chem. Soc. Jpn. 1989, 62, 709-716.

(66) Liu, R. Y., Conradie, J. Tris(beta-diketonato)chromium(III) complexes: Effect of the beta-diketonate ligand on the redox properties. Electrochim. Acta 2015, 185, 288-296.

(67) Wang, P., Miller, J. E., Henling, L. M., Stern, C. L., Frank, N. L., Eckermann, A. L., Meade, T. J. Synthesis and characterization of ruthenium and rhenium Nucleosides. Inorg. Chem. 2007, 46, 9853-9862.

(68) von Chrzannowski, L. S., Lutz, M., Spek, A. L. alpha-Tris(2,4-pentanedionato-kappa O-2,O')-cobalt(III) at 240, 210, 180, 150 and $110 \mathrm{~K}$. Acta Cryst. C 2007, 63, M283-M288.

(69) Mori, H., Yamagishi, A., Sato, H. Theoretical study on vibrational circular dichroism spectra of tris(acetylacetonato)metal(III) complexes: Anharmonic effects and low-lying excited states. J. Chem. Phys. 2011, 135. 
(70) Berova, N., Polavarapu, K., Nakanishi, R. W. Comprehensive Chiroptical Spectroscopy; Woody (eds.), Wiley: Hoboken, 2012; Vol. 2.

(71) Canary, J. W. Redox-triggered chiroptical molecular switches. Chem. Soc. Rev. 2009, $38,747-756$.

(72) Feringa, B. L. Molecular Switches, Wiley-VCH: Weinheim, 2001.

(73) Li, D., Wang, Z. Y., Ma, D. G. Electrically-controlled near-infrared chiroptical switching of enantiomeric dinuclear ruthenium complexes. Chem. Comm. 2009, 1529-1531.

(74) Isla, H., Crassous, J. Helicene-based chiroptical switches. C. R. Chimie 2016, 19, 3949.

(75) Autschbach, J. Computing Chiroptical Properties with First-Principles Theoretical Methods: Background and Illustrative Examples. Chirality 2009, 21, E116-E152.

(76) Srebro-Hooper, M., Autschbach, J. Calculating Natural Optical Activity of Molecules from First Principles. Annu. Rev. Phys. Chem. 2017, 68, DOI: 10.1146/annurev-physchem052516-044827.

(77) Autschbach, J., Jorge, F. E., Zlegler, T. Density functional calculations on electronic circular dichroism spectra of chiral transition metal complexes. Inorg. Chem. 2003, 42, 28672877.

(78) Fan, J., Seth, M., Autschbach, J., Ziegler, T. Circular Dichroism of Trigonal Dihedral Chromium(III) Complexes: A Theoretical Study based on Open-Shell Time-Dependent Density Functional Theory. Inorg. Chem. 2008, 47, 11656-11668.

(79) Autschbach, J. Calculating electronic optical activity of coordination compounds, in K. Poeppelmeier, J. Reedijk, (eds), Comprehensive Inorganic Chemistry II, volume 9, Elsevier, Oxford, UK, 2013, pp. 407-426. 
TOC graphic:

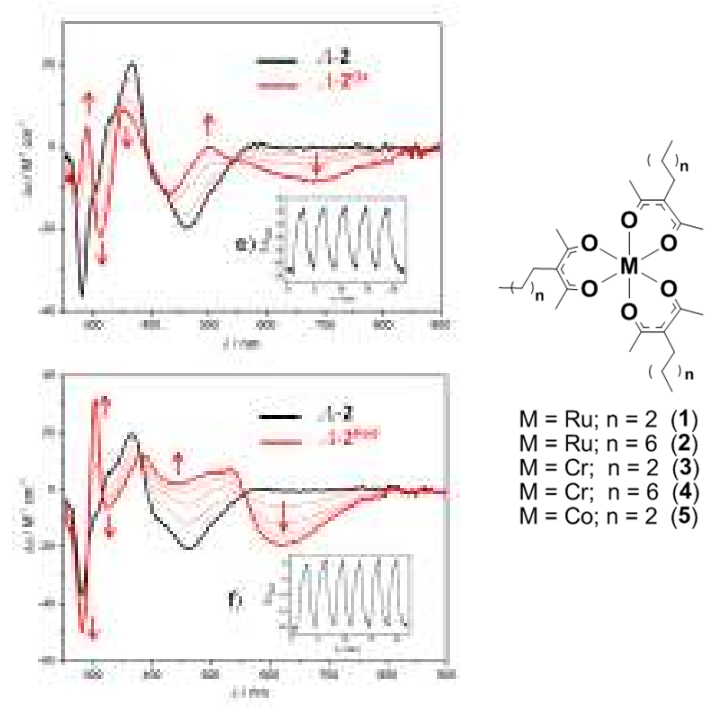

Synopsis: The paper reports the synthesis, optical resolution, characterization, spectroelectrochemical behavior and unprecedented chiroptical switching along with (TD)DFT analysis of tris( $\beta$-diketonato)complexes of $\mathrm{Ru}(\mathrm{III}), \mathrm{Cr}(\mathrm{III})$ and $\mathrm{Co}(\mathrm{III})$ involving 3butyl or 3-octyl substituted 2,4-dionato moiety. 